\title{
LA ALTERACIÓN DEL ORDEN DEL DÍA PARA APROBAR LAS LEYES DE REFERÉNDUM Y TRANSITORIEDAD. EL USO DEL ARTÍCULO 81.3 DEL REGLAMENTO DEL PARLAMENTO DE CATALUÑA
}

DANIEL FERNÁNDEZ CAÑUETO 
SUMARIO

1. INTRODUCCIÓN. 2. EL CONTENIDO DEL ARTÍCULO 81.3 DEL REGLAMENTO DEL PARLAMENTO DE CATALUÑA. 3. LAS CONSECUENCIAS DEL USO DEL ARTÍCULO 81.3 RPC PARA INTRODUCIR LAS PROPOSICIONES DE LEY DE REFERÉNDUM Y TRANSITORIEDAD EN EL ORDEN DEL DÍA. 4. LA JURISPRUDENCIA DEL TRIBUNAL CONSTITUCIONAL SOBRE LAS CUESTIONES PLANTEADAS DURANTE EL PROCEDIMIENTO DE APROBACIÓN DE AMBAS PROPOSICIONES DE LEY. 4.1 LA PROBLEMÁTICA DE SI LA MESA PODÍA HABER INADMITIDO A TRÁMITE AMBAS PROPOSICIONES DE LEY. 4.2 LA PROBLEMÁTICA DE SI EL ART. 81.3 RPC PERMITE QUE A SU TRAVÉS SE DESARROLLE AQUEL PROCEDIMIENTO LEGISLATIVO QUE SE ACABÓ UTILIZANDO PARA APROBAR AMBAS PROPOSICIONES DE LEY. 4.3 LA PROBLEMÁTICA SOBRE LA SUPRESIÓN DE LA POSIBILIDAD DE SOLICITAR DICTAMEN AL CONSEJO DE GARANTÍAS ESTATUTARIAS. 5. UNA POSIBLE RESOLUCIÓN DE LOS RECURSOS DE AMPARO PRESENTADOS POR EL GRUPO PARLAMENTARIO DE CIUDADANOS. 5.1 EN RELACIÓN CON LOS ACUERDOS DEL PLENO MEDIANTE LOS CUALES SE ALTERABA DEL ORDEN DEL DÍA PARA INTRODUCIR LAS PROPOSICIONES DE LEY DEL REFERÉNDUM Y DE TRANSITORIEDAD. 5.2 EN RELACIÓN CON LOS ACUERDOS DEL PLENO MEDIANTE LOS CUALES SE CREABA UN PROCEDIMIENTO LEGISLATIVO AD HOC PARA PROCEDER AL DEBATE Y VOTACIÓN DEFINITIVA DE LAS PROPOSICIONES DE LEY DEL REFERÉNDUM Y DE TRANSITORIEDAD. 6. LAS SSTC 10/2018 Y 27/2018 QUE RESUELVEN LOS RECURSOS DE AMPARO SOBRE LOS ACUERDOS DE LA MESA POR LOS QUE SE DESESTIMABA LA SOLICITUD DE DICTAMEN DEL CGE. 7. CONCLUSIÓN. 


\title{
LA ALTERACIÓN DEL ORDEN DEL DÍA PARA APROBAR LAS LEYES DE REFERÉNDUM Y TRANSITORIEDAD. EL USO DEL ARTÍCULO 81.3 DEL REGLAMENTO DEL PARLAMENTO DE CATALUÑ ${ }^{1}$
}

\author{
DANIEL FERNÁNDEZ CAÑUETO² \\ Profesor de Derecho Constitucional de la Universitat de Lleida
}

\section{INTRODUCCIÓN}

Desde finales de $2012^{3}$, tanto las instituciones autonómicas como la opinión pública controladas por aquel nacionalismo catalán que antaño no rehusaba formar parte del proyecto común estatal, han iniciado un proceso secesionista que ha puesto en duda el orden constitucional al negarse a respetar las resoluciones de su máximo intérprete y realizar una serie de actuaciones jurídico-políticas cuyo objetivo ha sido efectuar un referéndum de secesión contrario a la Carta Magna que les permitiera legitimar la construcción de la futura república catalana (STC 103/2008, 31/2015, 32/2015, 138/2015, 259/2015, 114/2017 y 124/2017).

1 Este trabajo se inserta en las actividades del Grupo de Estudios sobre Democracia y Constitucionalismo (GEDECO, grupo consolidado Generalitat 2014) y del proyecto de investigación financiado por el MINECO DER 2012-37567 sobre «Democracia multinivel: la participación de los ciudadanos y de los entes territoriales en los procesos de decisión pública».

2 Departamento de Derecho Público. Facultad de Derecho, Economia y Turismo. C. Jaume II, 73. 25001 Lleida. Email: daniel@dpub.udl.cat

3 Sobre la razón por la cual la sentencia del Tribunal Constitucional de 2010 en relación al Estatuto de Autonomía de Cataluña no fue el inicio del movimiento secesionista, son de especial interés: Dowling. A (2013), La reconstrucció nacional de Catalunya. Els antecedents polítics del procés, Barcelona, Pasado\&Presente, pág. 247-331; Amat. J, (2015), El llarg procés: Cultura i política a la Catalunya contemporànea (1937-2014), Tusquets; Víctor Saura, «Con el Constitucional no empezó todo», en eldiario.es, 21-02-2016. 
Para realizar dicho proceso de secesión, el gobierno de la Generalitat de Cataluña y la mayoría parlamentaria que lo sustentaba anunciaron la aprobación de dos proposiciones de ley: una de referéndum de autodeterminación para que la futura votación tuviera un marco normativo y otra de transitoriedad jurídica y fundacional de la república para que no existiera un vacío legal durante la transición hacia el nuevo Estado catalán. Ahora bien, como eran perfectamente conscientes de que ambas colisionaban abiertamente con el orden constitucional vigente, urdieron una estrategia para que su tramitación parlamentaria se realizara a través de un mecanismo jurídico que les permitiera aprobarlas sin que pudiera existir una impugnación del Gobierno o una suspensión por parte del Tribunal Constitucional antes de que éstas fueran votadas en el parlamento autonómico catalán.

Así pues, para tratar de soslayar la legalidad constitucional y sortear (o como mínimo dificultar) tanto las impugnaciones del gobierno estatal como las actuaciones del máximo intérprete constitucional, la mayoría parlamentaria independentista promovió una reforma del art. 135.2 del Reglamento del parlamento de Cataluña ${ }^{4}$ (en adelante RPC) con el fin de aprobar ambas proposiciones de ley a través suyo 5 .

4 Mientras el contenido íntegro del artículo 135 del RPC antes de la reforma era el siguiente: «1. Un proyecto de ley puede ser tramitado directamente y en lectura única por el Pleno del Parlamento o por una comisión, si la naturaleza del proyecto lo aconseja o si la simplicidad de la formulación lo permite. La tramitación en lectura única debe ser acordada por el Pleno del Parlamento, a propuesta del Gobierno, de la Mesa del Parlamento, oída la Junta de Portavoces o a iniciativa de esta. 2. Las proposiciones de ley firmadas por todos los grupos parlamentarios pueden ser tramitadas en lectura única por el Pleno del Parlamento o por una comisión, de conformidad con lo establecido por el apartado 1. Una vez ejercida la iniciativa y planteada la petición para que sea tramitada en lectura única, la Mesa del Parlamento ordena la publicación de la proposición de ley y su remisión al Gobierno, de conformidad con lo dispuesto por el artículo 111.2. 3. El debate de la iniciativa legislativa en lectura única sigue las normas establecidas para los debates de totalidad; finalmente, el conjunto de la iniciativa se somete a una sola votación». El apartado segundo que se reformó y posteriormente fue suspendido estaba redactado así: «2. El grupo parlamentario promotor de una proposición de ley puede solicitar su tramitación por el procedimiento de lectura única. Corresponde al Pleno del Parlamento acordarla, a propuesta de la Mesa, oída la Junta de Portavoces o a iniciativa de esta, siempre que la proposición de ley cumpla los requisitos de habilitación establecidos por el apartado $1 »$.

5 Cuando la propuesta de reforma del Reglamento llegó al Pleno del Parlamento de Cataluña, el diputado socialista Ferran Pedret i Santos afirmaría que «tanto el Gobierno como los grupos parlamentarios, han estado anunciando a diestro y siniestro cuál era la intención de esta reforma reglamentaria. I no sólo lo han dicho en declaraciones a los medios de comunicación, sino que incluso en la ponencia [...] se nos manifestó sin ningún tipo de problema que ésta era una reforma que, evidentemente, estaba enfocada a permitir una tramitación exprés, con el mínimo de impedimentos posibles, de aquellas leyes de desconexión que van mutando de nombre». Asimismo, el diputado de CSQP Joan Coscubiela Conesa expondría que «de lo que estamos tratando no es sólo de la reforma del Reglamento, sino de la ley del referéndum [...] La utilización de este Reglamento para intentar aprobar sin garantías democráticas la ley de referéndum ha sido y sigue siendo la principal razón de nuestra oposición a la reforma». Y, por último, la diputada de la CUP-CC, Anna Gabriel, manifestaría que «todo lo que se sale de la legislación vigente para ustedes es de golpe de estado hacia arriba. No tenemos ningún problema en decir que, si la legislación vigente no reconoce el derecho de autodeterminación de los pueblos, es una legislación que se debe cambiar. Y si no se puede cambiar, 
Pero, como la admisión a trámite del recurso de inconstitucionalidad presentado por el Gobierno del Estado en base al dictamen del Consejo de Estado ${ }^{6}$ suspendió dicho texto reformado e impidió que el nuevo art. 135.2 RPC fuera utilizado ${ }^{7}$, la mayoría parlamentaria secesionista tuvo que replantearse la estrategia, eligiendo finalmente el art. 81.3 RPC como procedimiento alternativo a través del cual acabarían aprobando tanto lo proposición de ley del referéndum como la de transitoriedad.

La definitiva aprobación de ambas proposiciones de ley gracias al uso del art. 81.3 RPC, recibió diversas y contundentes críticas por parte de los grupos parlamentarios de la oposición al considerar que, a su través, la mayoría parlamentaria de JuntsxSí y la CUP habían creado un procedimiento legislativo ad hoc donde se les impedía realizar funciones básicas del mismo como examinar durante 48 horas el texto antes de su discusión, presentar enmiendas a la totalidad o solicitar un dictamen al Consejo de Garantías Estatutarias (en adelante CGE). Reproches estos sobre el procedimiento utilizado para la tramitación de ambas proposiciones de ley que se transformarían en sendos recursos de amparo de los grupos parlamentarios Socialista y de Ciudadanos por presunta vulneración del derecho fundamental al ejercicio del cargo público 23.2 CE. Uniéndose a los respectivos incidentes de ejecución de sentencias planteados por el Gobierno contra los acuerdos que permitieron su tramitación ${ }^{8}$, los posteriores recursos de inconstitucionalidad del

se debe desbordar [...] Nosotros daremos apoyo a una reforma del Reglamento si sirve para levantar las barreras a este pueblo para autodeterminarse [...] y si sirve para que la gente pueda votar el 1 de octubre, apoyaremos una reforma del Reglamento, claro que sí», en Diari de sessions del Parlament de Catalunya, XI legislatura, quart período, sèrie P, número 76, Sessió 40, reunió segona, dimecres 26 de juliol de 2017, pág. 58-79.

6 En el FJ VIII del Dictamen núm. $722 / 2017$ de la Comisión permanente del Consejo de Estado se acabará manifestando que, «en el caso de la reforma del Parlamento de Cataluña, la combinación de las dos circunstancias ya señaladas, a saber, que no se haya reconocido a la minoría parlamentaria el derecho a presentar enmiendas, de una parte, y que se le haya privado de toda participación en la decisión de iniciar el trámite de lectura única, consagrando la regla de la mayoría simple, de otra, privan a la minoría de la garantía de algún instrumento de participación en el procedimiento de lectura única distinto de su mera intervención en el debate de totalidad. Tal circunstancia puede suponer una vulneración del derecho de participación política de la minoría parlamentaria en condiciones de igualdad ex artículo 23.2 de la Constitución y 29 del Estatuto de Autonomía de Cataluña».

7 Recurso que ha sido resuelto en la STC 139/2017, declarándose constitucional la reforma del Art. 135.2 RPC al considerar que existe una interpretación cuyo contenido permite que el precepto se ajuste a la Constitución siempre que se desarrolle vía reglamentaria o uso parlamentario un procedimiento de enmiendas (o equivalente) para garantizar el ejercicio del cargo público en condiciones de igualdad.

${ }^{8}$ En relación a ellos, los AATC 123/2017 y 124/2017 han abordado dichos incidentes de ejecución, acabando por declarar la nulidad tanto de los acuerdos de la Mesa de admisión a trámite de ambas proposiciones de ley como la nulidad de los acuerdos del Pleno por los que se incluye en el orden del día el debate y votación de ambas proposiciones de ley y se suprimen los tramites esenciales del procedimiento legislativo. 
Gobierno contra el contenido de las dos leyes ${ }^{9}$ y la subsiguiente querella de la Fiscalía tanto contra la mayoría de los miembros de la Mesa del Parlamento como contra todo el Gobierno de la Generalitat por tramitarlas y ejecutarlas a sabiendas de que colisionaban abiertamente con el orden constitucional vigente e infringían los incidentes de ejecución del TC (AATC 141/2016, 170/2016, 24/2017).

Fruto de todo ello, el presente texto tiene como objetivo analizar si el uso que se hizo del art. 81.3 RPC para tramitar dichas proposiciones de ley es o no contrario a lo establecido en nuestra norma fundamental. Cuestión para la cual lo dividiremos en cinco partes: una primera que examinará el contenido del art. 81.3 RPC, una segunda donde se describirá tanto el proceso parlamentario que siguieron las proposiciones de ley de referéndum y transitoriedad como los recursos de amparo que después se presentaron, una tercera donde se analizará la doctrina del TC sobre las cuestiones planteadas en la sección anterior, una cuarta que tratará de esbozar una posible solución para los recursos de amparo que actualmente están pendientes de sentencia por parte del máximo intérprete constitucional y una quinta donde se analizará las SSTC 10/2018 y 27/2018 que resuelven los recursos de amparo del grupo parlamentario socialista sobre los acuerdos de la Mesa por los que se desestimaba la solicitud de dictamen del CGE.

\section{EL CONTENIDO DEL ARTÍCULO 81.3 RPC}

El presente artículo sobre la alteración del orden del día del Pleno no es exclusivo del reglamento parlamentario catalán, sino que puede encontrarse tanto en el reglamento del Congreso ${ }^{10}$ como en los demás reglamentos de los parlamentos autonómicos ${ }^{11}$. Ahora bien, aunque dicho precepto exista de manera similar en los demás

9 Recurso de inconstitucionalidad n. ${ }^{\circ}$ 4334-2017, contra la Ley del Parlamento de Cataluña 19/2017, de 6 de septiembre, del Referéndum de Autodeterminación (BOE, núm. 216, Sec. I, pág. 882000) y recurso de Inconstitucionalidad n. ${ }^{4} 4386-2017$, contra la Ley 20/2017, de 8 de septiembre, de la Comunidad Autónoma de Cataluña denominada «Ley de transitoriedad jurídica y fundacional de la República»(BOE, núm. 22, Sec. I, pág. 89899). Existiendo ya sentencias sobre ellas (STC 114/2017 y 124/2017) en la que se estiman los recursos y, en consecuencia, se declara la inconstitucionalidad de ambas leyes.

${ }^{10}$ En dicho reglamento podemos encontrar la modificación del orden del día en el art. 68. Por el contrario, el Reglamento del Senado (art. 71.4) será diferente a lo establecido tanto en el Congreso como en los demás Reglamentos autonómicos. Cf. Santaolalla López, F. (2013), Derecho parlamentario español, Madrid, Dykinson, pág. 236-238; Carbajal Iranzo, I. (2012), «art. 67-68», en María Rosa Ripollés Serrano, Comentarios al reglamento del Congreso de los Diputados, Madrid, Congreso de los Diputados, pág. 549-555.

11 Art. 116 del Reglamento de las Cortes de Aragón, art. 66 Reglamento de las Cortes Valencianas, art. 93 del Reglamento de la Asamblea Regional de Murcia, art. 73 del Reglamento del Parlamento de Andalucía, art. 73 del Reglamento de la Asamblea de Extremadura, art. 76 del Reglamento del Parlamento canario, art. 87 del Reglamento de las Cortes de Castilla la Mancha, art. 107 del Reglamento de la Asamblea de Madrid, art. 58 del Reglamento del Parlamento de la Rioja, art. 73 del Reglamento del Parlamento de las Islas Baleares, art. 79 del Reglamento del Parlamento de Navarra, Art. 70 del 
reglamentos parlamentarios, sí que es posible hacer tres aseveraciones específicas sobre él: la primera es que, fruto de una paulatina ampliación del RPC, su contenido ha pasado de estar fijado en el art. 61.4 RPC en 1980 a establecerse en el art. 81.3 RPC en 2017; la segunda es que, aun siendo cierto lo anterior, el precepto siempre se ha ubicado en el Titulo IV (del funcionamiento del parlamento), Capítulo I (las disposiciones generales del funcionamiento), Sección segunda (el orden del día); y la tercera aseveración es que, más allá de las variaciones que haya podido sufrir su redacción, la alteración del orden del día ha mantenido un contenido casi idéntico a lo largo del tiempo, cuestión que puede verse en la similitud que existe entre el art. 61.4 del RPC en 1980 donde se establecía que

«L'ordre del dia del Ple podrà ser alterat quan aquest així ho acordara, a proposta del President o a petició de dos Grups parlamentaris o d'una cinquena part dels membres de la Cambra. L'ordre del dia d'una Comissió podrà ésser alterat quan aquesta així ho acordara, a proposta del seu President o a sol-licitud de dos Grups parlamentaris o d'una cinquena part dels Diputats que formen part. Quan es tractarà d'incloure-hi un assumpte, aquest haurà d'haver complert els tràmits reglamentaris que li permetran d'ésser-hi inclòs, llevat d'acord explícit en sentit contrari, per majoria absoluta del Ple de la Cambra o de la Comissió corresponent» ${ }^{12}$.

Y el actual art. 81.3 RPC cuya redacción fija que

«El orden del día del Pleno puede ser alterado si este lo acuerda, a propuesta del presidente o a petición de dos grupos parlamentarios o de una quinta parte de los miembros del Parlamento, y cuando así lo obliga el cumplimiento de una ley. Si debe incluirse un asunto, este debe haber cumplido los trámites reglamentarios que lo permiten, salvo un acuerdo explícito en sentido opuesto, por mayoría absoluta».

En cuanto al contenido del propio art. 81.3 RPC, es posible extraer, como mínimo, tres grandes ideas. La primera es que, como el orden del día constituye la relación de asuntos que un órgano ha de examinar en una determinada sesión y su establecimiento es imprescindible porque constituye una triple garantía en el interior de la vida parlamentaria (de buen gobierno y administración, de protección de la autonomía de los órganos del Parlamento frente a la injerencia de terceros y de defensa de las minorías

\footnotetext{
Reglamento del Parlamento de Cantabria, art. 91 de del Reglamento de la Junta General del Principado de Asturias, art. 73 del Reglamento del Parlamento de Galicia y art. 78 del Reglamento del Parlamento Vasco. Sobre el funcionamiento de los parlamentos en general véase: Oñate, P (edit.). (2006): Organización y funcionamiento de los parlamentos autonómicos, Valencia, Tirant lo Blanch.

12 BOPC 007/01. Al no encontrar el documento en castellano, una traducción aproximada no oficial del mismo podría ser la siguiente: «el orden del día del Pleno podrá ser alterado cuando así lo acordara, a propuesta del presidente o a petición de dos Grupos parlamentarios o una quinta parte de los miembros de la Cámara. El orden del día de una Comisión podrá ser alterado cuando esta así lo acuerde, a propuesta de su Presidente o a solicitud de dos Grupos parlamentarios o de una quinta parte de los Diputados que formen parte. Cuando se tratará de incluir un asunto, este tendrá que haber cumplido los trámites reglamentarios que le permitan ser incluido, menos cuando haya un acuerdo explícito en sentido contrario, por mayoría absoluta del Pleno de la Cámara o de la Comisión correspondiente».
} 
frente a la mayoría $)^{13}$, la importancia de dicho precepto reside en que tiene como función básica determinar la forma y manera en que puede ser alterado ese orden del día prefijado. La segunda idea es que, en base a lo afirmado por los letrados del Parlamento de Cataluña ${ }^{14}$ y como la redacción del art. 81.3 RPC comporta una mayor laxitud que la del Congreso o la de los demás reglamentos parlamentarios (pues en ellos la modificación del orden del día está sujeta a la condición de que si la iniciativa no ha seguido los trámites reglamentarios correspondientes su inclusión debe realizarse por unanimidad $)^{15}$, es perentorio interpretar el art. 81.3 RPC de la siguiente manera: aunque en él se permita que la mayoría absoluta del Parlamento ostente la capacidad de incluir en el orden del día cualquier asunto parlamentario que no haya completado todos los trámites previstos en el propio reglamento, ello no puede comportar en ningún caso una lectura al margen de las facultades básicas que el RPC otorga a los diputados, del contenido esencial que posee el art. $23.2 \mathrm{CE}^{16}$ o de los trámites inexcusables que debe tener cualquier procedimiento legislativo del Reglamento parlamentario catalán. Interpretación esta que, de no hacerse así, comportaría que a su través la mayoría parlamentaria tuviera el poder de excluir trámites que se erigen en garantía de los derechos de los diputados. Y la tercera idea es que, uno de los vocablos que puede dar lugar a controversia es el significado de la palabra «asunto», pues es un concepto jurídico indeterminado cuya definición es de vital importancia porque fijará qué cuestiones puede alterar el orden del día. Aclaración del término que, por el momento, ni la doctrina ni la jurisprudencia han realizado, de manera que no es posible establecer de antemano y con exactitud cuáles son los requisitos o límites que dicha expresión ostenta.

En suma, el art. 81.3 RPC ha sido de gran interés para los grupos parlamentarios secesionistas por tres razones. En primer lugar, porque a su través se puede modificar el orden del día prefijado, incluyendo cuestiones controvertidas sin que el máximo intérprete constitucional o el Gobierno tengan tiempo para reaccionar antes de su debate y votación. En segundo lugar, porque permite que la mayoría absoluta incluya asuntos que no hayan completado todos los trámites previstos en el propio regla-

${ }^{13}$ Cf. Santaolalla López, F., Derecho parlamentario español..., pág. 233-236; Requejo Rodríguez, P. (2000): Democracia parlamentaria y principio minoritario, Barcelona, Ariel, págs. 152-155; Seseña Santos, L. (2016), «El pleno y la diputación permanente», en Xosé Antón Sarmiento Méndez, Manual AELPA del Parlamentario, España, AELPA y Wolters Kluwer, pág. 199-205.

14 «Observacions i propostes jurídiques i tècniques a la reforma del reglament», Informe de los Letrados del Parlamento de Cataluña, Barcelona, 21 de junio de 2017, pág. 8-9.

15 Carbajal Iranzo, I., «Art. 67-68», Comentarios al reglamento del Congreso de los Diputados..., pág. 552-553.

16 Sobre el contenido esencial del artículo 23.2 de la Constitución española Cf. Manuel Pulido Quecedo, El acceso a los cargos y funciones públicas: un estudio del artículo 23.2 de la Constitución, Civitas, Madrid, 1992; Enric Fossas Espadaler, El derecho de acceso a los cargos públicos, Tecnos, Madrid, 1993; Esther Martín Núñez, El régimen Constitucional del Cargo Público Representativo, CEDECS, Barcelona, 1996; Javier García Roca, Cargos Públicos Representativos. Un estudio del artículo 23.2 de la Constitución, Aranzadi, Pamplona, 1998; Miguel Ángel Presno Linera, «La representación política como derecho fundamental», en Fundamentos: Cuadernos monográficos de teoría del estado, derecho público e historia constitucional, Núm. 3 (2004); Gonzalo Arruego Rodríguez, Representación política y derecho fundamental, CEPC, Madrid, 2005. 
mento sin necesidad de buscar la unanimidad. Y, en tercer lugar, porque todavía no existe ni doctrina ni jurisprudencia consolidada que haya determinado los requisitos o límites de los «asuntos» que pueden alterar el orden del día, de manera que bien puede interpretarse que a su través es posible incluir proyectos o proposiciones de ley. Cuestiones todas ellas que, unidas, permiten comprender porque la mayoría parlamentaria favorable a la independencia optó por dicho artículo como alternativa para tramitar las proposiciones de ley de referéndum y de transitoriedad jurídica.

\section{LAS CONSECUENCIAS DEL USO DEL ARTÍCULO 81.3 RPC PARA INTRODUCIR LAS PROPOSICIONES DE LEY DE REFERÉNDUM Y TRANSITORIEDAD EN EL ORDEN DEL DÍA}

La manera en que se aprobaron las proposiciones de ley de referéndum y de transitoriedad jurídica los días 6 y 7 de septiembre de $2017^{17}$ fue esencialmente la misma, razón por la cual su análisis puede hacerse de manera conjunta.

Ambos procedimientos se iniciaron con un escrito de los grupos parlamentarios de JuntsxSí y la CUP a la Mesa del Parlamento autonómico para que ésta admitiera a trámite cada una de las dos proposiciones de $l e y^{18}$, de manera que pudieran ser debatidas, y si fuera el caso aprobadas, durante los Plenos que se iban a celebrar ${ }^{19}$. La posterior calificación y admisión a trámite por parte de la $\mathrm{Mesa}^{20}$ en base a un art. 105.4 RPC que los convirtió en procedimientos de urgencia extraordinarios permitió que, al inicio de cada uno de los dos Plenos, Marta Rovira i Vergés (portavoz del grupo parlamentario de JuntsxSí) solicitara la palabra para requerir a la Presidenta del Parlamento de Cataluña una doble votación: primero que, en virtud del art. 81.3 RPC, se votara una alteración del orden del día para incorporar en él cada una de las proposiciones de ley (el día 6 la de referéndum y el día 7 la de transitoriedad); y, segundo, que en base al art. 81.3 in fine, también se votara la supresión de

${ }^{17}$ El número de expediente completo del Parlamento de Cataluña donde se pueden encontrar todos los documentos sobre la evolución de la propuesta de reforma es Tram. 202-00065/11 para la Ley de referéndum de autodeterminación y Tram. 202-00066/11 para la Ley de transitoriedad jurídica y fundacional de la república.

${ }^{18}$ La proposición de ley del referéndum de autodeterminación fue presentada el 31 de julio de 2017 por los grupos parlamentarios de JuntsxSí y CUP (publicada en el «Boletín Oficial del Parlamento de Cataluña» núm. 500, de 6 de septiembre de 2017). En cambio, la proposición de ley denominada «de transitoriedad jurídica y fundacional de la República» fue presentada por los mismos grupos parlamentarios el 28 de agosto de 2017 en el Parlamento de Cataluña, cuyo texto aparece publicado en el «Boletín Oficial del Parlamento de Cataluña» núm. 507, de 7 de septiembre de 2017.

19 BOPC 500/11 de 06/09/2017 y BOPC 501/11 de 07/09/2017.

${ }^{20}$ La votación sobre la admisión a trámite de ambas proposiciones de ley tuvo cinco votos a favor de JuntsxSí y CSQEP frente a dos en contra de C's y PSC. Aunque no disponemos del documento con los motivos de admisión a trámite de la mayoría de la Mesa, no es ilógico pensar que, si dicho escrito existió, los motivos aducidos en él fueron análogos que los alegados posteriormente por los servicios jurídicos del Parlamento catalán frente al TC (véase nota 50). 
todos los trámites parlamentarios menos la calificación y admisión a trámite (ya realizada), la publicación de la iniciativa, un breve periodo de presentación de enmiendas al articulado (dos horas) ${ }^{21}$ y, por último, el debate y votación final en el Pleno $^{22}$. Petición esta que defendería tanto la propia Marta Rovira como Ana Gabriel (portavoz del grupo parlamentario CUP) aduciendo que, como las diversas sentencias del TC impedían que ambas proposiciones de ley se debatieran por los cauces habituales $^{23}$, era perentorio utilizar el art. 81.3 RPC para evitar que dicho tribunal pudiera suspender en cualquier momento el procedimiento, cuestión que hubiera imposibilitado tanto la posterior firma del decreto de convocatoria del referéndum como la entrada en vigor de la Ley de transitoriedad ${ }^{24}$.

La solicitud de la portavoz de JuntsxSí con el apoyo del grupo parlamentario de la CUP tuvo tres consecuencias. La primera fue una serie de suspensiones del Pleno para que la Mesa y la Junta de Portavoces se reunieran con el objetivo de estudiar las reconsideraciones tanto sobre la admisión a trámite de ambas proposiciones de ley como sobre las propuestas de alteración del orden del día y supresión de diversos trámites parlamentarios $^{25}$, siendo todas ellas posteriormente rechazadas ${ }^{26}$. La segunda conse-

${ }^{21}$ Sobre el derecho de enmienda Cf. Arce Janariz, A., (mayo-agosto 1994): «El derecho de enmienda visto por el Tribunal Constitucional», en Revista Española de Derecho Constitucional, año 14, núm. 41; Soriano Hernández, E y Visiedo Mazón, F.J., (2000), Las enmiendas en el procedimiento legislativo, Murcia, AELPA; Redondo García, A.M. (2001), El derecho de enmienda en los procedimientos legislativos de las Cortes Generales, Congreso de los Diputados, Madrid; García Escudero, P. (2012), «Los límites al derecho de enmienda en la reforma constitucional y la nueva doctrina del Tribunal Constitucional sobre las enmiendas a iniciativas legislativas», en Revista "Cuadernos Manuel Giménez Abad», Núm. 3.

22 DSPC-P 80 de 6 de septiembre de 2017, pág. 16; DSPC-P 81, de 7 de septiembre de 2017, pág. 76-77. Sobre los trámites que debían ser suprimidos, Marta Rovira afirmaría el 6 de septiembre que, «concretamente, pedimos que se eximan el debate a la totalidad de la ley y el Dictamen del Consejo de Garantías Estatutarias, tal como está previsto en el mismo Reglamento del Parlamento [...] Entendemos que con esta exención no queda afectado el control de legalidad, porque siempre se puede hacer con posterioridad a la votación por los tribunales ordinarios [...] I porque si hubiéramos llegado al punto de tener un dictamen previo del Consejo de Garantías Estatutarias [...] si hubiéramos podido utilizar la tramitación ordinaria y hoy tuviéramos ese dictamen, podríamos estar delante de una votación idéntica a la que se plantea, porque en ningún caso las observaciones es realizadas en el dictamen son vinculantes y, por tanto, podríamos no haberlas incorporado al texto final que nosotros presentamos a votación» (DSPC-P 80, pág. 6). Haciendo al día siguiente una declaración análoga cuando aseveraba que, «en esta votación también queremos que quede muy claro que pedimos que se haga esta tramitación legal sin las solicitudes de informe al Consejo de Garantías Estatutarias porque consideramos que esta ley, la Ley de transitoriedad, claramente supera el marco estatutario y el marco constitucional» (DSPC-P 81, pág. 54).

${ }^{23}$ En referencia a las STC 103/2008, 31/2015, 32/2015, 138/2015, 259/2015 y los AATC 141/2016, 170/2016, 24/2017).

${ }^{24}$ DSPC-P 80/11, pág. 5-7 y DSPC-P 81/11, pág. 54-55.

25 DSPC-P 80/11, pág. 7-31 y DSPC-P 81/11, pág. 55-78.

${ }^{26}$ Durante el Pleno, los grupos de la oposición alegaron que se habían denegado las solicitudes de reconsideración sin que se les transmitiera por escrito los motivos de dichas denegaciones. Aunque no disponemos de los documentos donde se razone la denegación de la solicitud, creemos que éstos, si existieron, fueron en la misma dirección que las posteriores alegaciones que los servicios jurídicos del Parlamento catalán realizarían frente al TC (véase nota 50). 
cuencia fue el registro de diversas solicitudes por parte de algunos grupos parlamentarios de la oposición (C's, PSC y PP) para que la Mesa requiriese un dictamen al CGE sobre si dichas proposiciones de ley se ajustaban a la Constitución y el Estatuto de Autonomía ${ }^{27}$, peticiones que serían todas ellas desoídas mediante comunicación verbal en el Pleno ${ }^{28}$ y que provocaría que dichos grupos parlamentarios dirigiesen escritos directamente al CGE solicitándole que se pronunciase sobre la adecuación de las mismas al ordenamiento jurídico ${ }^{29}$. Y la tercera y última consecuencia fue que el secretario general del Parlamento de Cataluña (Xavier Muro) y su letrado mayor (Antoni Bayona) registraron un escrito dirigido a la Mesa, del cual posteriormente la Presidenta del Parlamento informaría en el Pleno, donde se efectuaban tres advertencias. La primera era que la tramitación tanto de la proposición de ley de referéndum como la de transitoriedad chocaban con la STC 259/2015 y los AATC 141/2016, 170/2016 y $24 / 2017^{30}$, haciendo que dicha tramitación no sólo pudiera comportar la exigencia de responsabilidades para los miembros de la Mesa fruto de su deber de impedir o paralizar cualquier iniciativa que supusiera ignorarlas ${ }^{31}$, sino que eso también podía extenderse a todos aquellos que realizaran actuaciones parlamentarias en el mismo sentido. La segunda advertencia era que el procedimiento de lectura única del art. 135.2 RPC estaba suspendido en virtud de la providencia del TC de 31 de julio de 2017 dictada en el recurso de inconstitucionalidad núm. 4062-2017. Y la tercera advertencia era que, como el uso dado al art. 81.3 RPC hacia que en la práctica el procedimiento tuviera unas características similares al ya suspendido de lectura única, debía tenerse en cuenta lo afirmado por el Dictamen del CGE de 7/2017 (en adelante DCGE) sobre la existencia de unos requisitos inexcusables en el seno del procedimiento legislativo ${ }^{32}$.

27 DSPC-P 80/11, pág. 18 y 25; DSPC-P 81/11, pág. 59 y 62.

28 Sobre dicha cuestión hacen referencia explícita los dos recursos de amparo presentados por el grupo parlamentario socialista los días 6 y 7 de septiembre ante el TC.

29 DSPC-P 81/11, pág. 65.

${ }^{30}$ En relación con ello, cabe afirmar que, en diciembre de 2015, el TC anuló por unanimidad la resolución independentista del Parlament que iniciaba el proceso de «desconexión» entre Cataluña y España. En julio de 2016, puso límites a la Comisión de Estudio Constituyente del Parlamento de Cataluña y advirtió especialmente a la Mesa de su deber de impedir o paralizar cualquier iniciativa que suponga ignorar o eludir los mandatos. En diciembre de 2016 suspendió el plan del Parlament para celebrar un referéndum independentista. En febrero de 2017 anuló la resolución que preveía una futura convocatoria de una consulta independentista. Y, por último, en julio de 2017 suspendió la reforma exprés del nuevo reglamento del Parlament que permite impulsar leyes por la vía de urgencia y en lectura única. Cf. Auto 123/2017 FJ 2.

31 De hecho, la Mesa las había inadmitido en cuatro ocasiones anteriores, la última el martes 5 de septiembre.

32 DCGE 7/2017, de 6 de julio, sobre la Propuesta de reforma parcial del Reglamento del Parlamento, pág. 45. En éste se afirma que «determinados trámites en la aprobación de una iniciativa legislativa como son su calificación y admisión; la publicación; el debate y presentación de enmiendas, cuando proceda, y el sometimiento a las garantías de control, fijadas por el Estatuto y las leyes (solicitud de dictamen al Consell de Garanties), además de constituir elementos inherentes al ius in officium de los diputados, son elementos esenciales e inexcusables del procedimiento legislativo asegurado por la Constitución y el Estatuto y desarrollado directamente en la norma primaria del Reglamento del Parlament». 
Rechazadas por la Mesa las reconsideraciones, desatendidas las solicitudes de petición de dictamen al CGE, informados todos sobre las posibles consecuencias de seguir con la tramitación de las proposiciones de ley y manifestada en reiteradas ocasiones la disconformidad de los grupos parlamentarios de la oposición con el procedimiento que se estaba utilizando al considerar que se podían estar vulnerando sus derechos de ejercicio del cargo público (art. 23.2 CE) al no disponer ni de 48 horas para examinar el texto de las leyes (art. 82 RPC) ni permitirles solicitar un dictamen al CGE (art. 76.2.b y 77.3 EAC; 16.1.b y 23.b LCGE) ${ }^{33}$; la Presidenta del Parlamento autonómico reanudaría la sesión por considerar que el Pleno era «soberano» ${ }^{34}$, permitiendo un debate tras el cual se aprobaría por la vía excepcional del art. 81.3 RPC tanto la alteración del orden del día ${ }^{35}$ como la exención de los trámites anteriormente explicitados ${ }^{36}$.

Una vez transcurrido el periodo de presentación de enmiendas al articulado y de que se volviera a suspender en varias ocasiones el Pleno para que la Mesa y la Junta de Portavoces resolvieran diversas solicitudes de reconsideración sobre la posibilidad de presentar enmiendas a la totalidad ${ }^{37}$, el CGE emitiría un acuerdo el día 6 de septiembre y otro el día 7 donde realizaría dos importantes observaciones. La primera era que las anteriores peticiones de dictamen realizadas por los grupos parlamentarios directamente al CGE no eran formalmente válidas, pues

«no han sido enviadas mediante el correspondiente escrito de admisión y calificación de la Mesa del Parlament, en los términos establecidos por el artículo 26.1 LCGE. Sobre este aspecto, debemos recordar que el órgano parlamentario competente con carácter exclusivo para admitir y calificar todas las iniciativas parlamentarias es la Mesa, incluida la solicitud de dictamen ${ }^{38}$.

Y la segunda observación era que, como ya se había advertido en el DCGE 7/2017 FJ 3 y 4, existían determinados trámites que no podían ser ignorados durante el procedimiento legislativo por mucho que se utilizara el art. 81.3 RPC para su inclusión en el orden del día. Siendo uno de ellos el derecho a solicitar un dictamen del CGE, pues

33 RI 4334/2017, pág. 10-14.

34 DSPC-P 80/11, pág. 13. Opinión que compartiría con la portavoz del grupo parlamentario JuntsxSí porque, en su intervención para pedir la modificación del orden del día, aseveraría que «entendemos, finalmente [...] que el Pleno es soberano y puede tomar esta decisión por mayoría absoluta, tal y como fija el Reglamento en su artículo 81.3» (DSPC-P 80/11, pág. 6).

35 En cuanto a la Ley de referéndum del día 6 de septiembre hubo 72 votos a favor, 60 en contra y 3 abstenciones. En cambio, por lo que respecta a la Ley de transitoriedad del día 7 de septiembre hubo 70 votos a favor, 19 en contra y 2 abstenciones. Cf. DSPC-P 80/11, pág. 16 y DSPC-P 81/11, pág. 78.

36 Por lo que respecta a la Ley de referéndum del día 6 de septiembre hubo 69 votos a favor, 3 en contra y ninguna abstención. En cambio, en cuanto a la Ley de transitoriedad del día 7 de septiembre hubo 70 votos a favor, 19 en contra y 2 abstenciones para la de transitoriedad. Cf. DSPC-P 80/11, pág. 16 y DSPC-P 81/11, pág. 78.

37 DSPC-P 80/11, pág. 57-66; DSPC-P 81/11, pág. 109.

38 Acuerdo del Pleno del Consell de Garanties Estatutàries, de 6 de septiembre de 2017, pág. 3. 
«todas las proposiciones de ley, sin excepción, en fase de tramitación en el Parlament de Cataluña y antes de ser aprobadas definitivamente, deben poder ser objeto de solicitud de dictamen ante este Consell, visto su carácter preceptivo si así lo peticionan los sujetos legitimados. La mencionada facultad constituye un derecho de los parlamentarios garantizado por el Estatuto y la legislación que lo desarrolla, y no puede limitarse por medio de ninguna decisión de un órgano parlamentario. En el caso de que se imposibilite su ejercicio, la decisión adoptada es susceptible de ser objeto de recurso de amparo constitucional» ${ }^{39}$.

Aun con todas las críticas explicitadas hasta el momento, el debate no se detendría ${ }^{40}$. La posterior finalización del mismo comportó que la mayoría de grupos parlamentarios de la oposición (C's, PSC y PP) abandonaran el Pleno antes de la votación en señal de protesta, realizándose acto seguido la misma cuyo resultado fue la aprobación tanto de la proposición de ley de referéndum (72 votos a favor, ninguno en contra y 11 abstenciones) como la de transitoriedad (71 votos a favor, 10 en contra y ninguna abstención $)^{41}$.

Como ya hemos adelantado en la introducción, las consecuencias judiciales de todo ello fueron varias ${ }^{42}$, pero en relación con el procedimiento utilizado para la aprobación de ambas proposiciones de ley centraremos nuestra atención en los cuatro recursos de amparo que presentaron los grupos parlamentarios Socialista y de Ciudadanos $^{43}$ por presunta vulneración del art. 23.2 CE, estando los de Ciudadanos todavía pendientes de sentencia por parte del máximo intérprete constitucional. Sobre ellos, mientras que en los del grupo parlamentario Socialista únicamente se pedía la declaración de nulidad de los acuerdos de la Mesa de los días 6 y 7 de septiembre por los que se desestimaba tramitar la solicitud de dictamen del CGE, en los del grupo parlamentario de Ciudadanos también se solicitaba la declaración de nulidad tanto de los acuerdos del Pleno mediante los cuales se alteraba del orden del día como de aquellos otros en los que se aprobaba un procedimiento legislativo ad hoc para proceder al debate y votación de las proposiciones de ley del referéndum y de transitoriedad.

39 Acuerdo del Pleno del Consell de Garanties Estatutàries..., pág. 3.

40 DSPC-P 80/11, pág. 69-97; DSPC-P 81/11, pág. 110-132.

41 DSPC-P 80/11, pág. 97 y DSPC-P 81/11, pág. 132. Cf. BOPC 501/11 de 06/09/2017 y BOPC 508/11 de 07/09/2017.

42 Aparte de los recursos de amparo, es necesario hacer referencia a los incidentes de ejecución planteados por el Gobierno contra los acuerdos que permitieron la tramitación de las proposiciones de ley y cuya resolución se encuentra en los AATC 123/2017 y 124/2017, los recursos de inconstitucionalidad contra el contenido de la ley del referéndum y la de transitoriedad jurídica y fundacional de la República que ya han sido abordados en las STC 114/2017 y 124/2017 y, por último, la querella de la Fiscalía tanto contra la mayoría de los miembros de la Mesa del Parlamento como contra todo el Gobierno de la Generalitat por tramitar dichas proposiciones de ley a sabiendas que ello colisionaba abiertamente con el orden constitucional vigente e infringían los incidentes de ejecución del TC (AATC 141/2016, 170/2016, 24/2017).

${ }^{43}$ Mientras los dos recursos de los socialistas serían presentados el mismo día de los hechos, los dos recursos de Ciudadanos se presentarían el día 4 de diciembre. 
Las peticiones de amparo al TC tanto del grupo parlamentario Socialista como el de Ciudadanos sobre los acuerdos de la Mesa mediante los cuales se desestimaba tramitar la solicitud de dictamen del CGE vendrían respaldadas por tres fundamentos jurídicos concatenados: como quiera que el art. 23.2 CE es un derecho de configuración legal donde una vez introducidos en las leyes o los Reglamentos parlamentarios éstos pasan a formar parte del ius in officium del parlamentario, dado que el RPC y la Ley 2/2009 legitiman a los recurrentes a pedir un dictamen al CGE y como los solicitantes de amparo han agotado cualquier vía parlamentaria de resolución de conflictos pues ha sido rechazado el escrito de reconsideración por parte de la Mesa (STC 161/1988) ${ }^{44}$, «la no tramitación de oficio por parte de la mesa de la solicitud de dictamen [...] supone una grave vulneración del artículo 23.2 de la Constitución respecto a los citados miembros» ${ }^{45}$.

En cambio, las específicas peticiones de amparo del grupo parlamentario de Ciudadanos por los acuerdos del Pleno mediante los cuales se alteraba del orden del día y aquellos otros por los que se creaba un procedimiento legislativo ad hoc para aprobar las proposiciones de ley del referéndum y de transitoriedad, se apoyarían en el siguiente conjunto de ideas: como quiera que ambas proposiciones de ley son evidentemente inconstitucionales, como la interpretación del RPC fue opuesta a la mayor efectividad de los derechos de las minorías dado que se creó un procedimiento nuevo con la única intención de vaciar la participación efectiva e igual de todos los diputados, como dicho nuevo procedimiento suprimía derechos de los diputados (pues éstos no obtuvieron la documentación objeto de debate y votación con cuarenta y ocho horas de antelación, se impidió solicitar dictamen al CGE, no se admitieron enmiendas a la totalidad y se concedieron solo dos horas para las enmiendas al articulado), como la función legislativa es la más relevante, como ésta se ejerce mediante las facultades que establecen los procedimientos regulados por el Reglamento y, finalmente, como «el disfrute y ejercicio de los derechos reglamentarios en relación con el procedimiento legislativo forma parte del estatus jurídico delimitado por el

${ }^{4}$ Cf. Marco Fernández Gutiérrez, (2016) «El acto parlamentario y su control jurisdiccional», en Asamblea: revista parlamentaria de la Asamblea de Madrid, Núm. 35, págs. 123. Sobre esto, el autor advierte que «el recurso de amparo es [...] un recurso jurisdiccional subsidiario, cuya admisión se vincula al agotamiento de todas las vías previas que el ordenamiento jurídico ofrece para la reparación del derecho fundamental vulnerado». Asimismo, sobre dicha específica cuestión véase: Pérez Serrano-Jáuregui, N. (1981): «Hacia una teoría de los actos parlamentarios», en Revista de Derecho Político, n. 9; Aranda Álvarez, E. (1998): Los actos parlamentarios no normativos y su control jurisdiccional, Madrid, Centro de Estudios Políticos y Constitucionales, Biglino Campos, P. (1999), «Algunas consideraciones acerca de la eficacia de los actos parlamentarios», en Asamblea: revista parlamentaria de Asamblea de Madrid, n. 1; Torres Muro, I. (2010), «El control jurisdiccional de los actos parlamentarios. La experiencia española», en Revista de la Red de Expertos Iberoamericanos en Parlamentos, Núm. 6, pág. 7-10; Pascual Mateo, F. (2014), Fuentes y control del Derecho parlamentario y de la Administración parlamentaria, Madrid, Centro de Estudios Políticos y Constitucionales.

45 Aunque también en los recursos del grupo parlamentario de Ciudadanos se argumentaría de manera parecida, dicho específico entrecomillado puede encontrarse en los dos recursos de amparo del grupo parlamentario Socialista. 
art. 23.2 CE», debe acabar afirmándose que si el cumplimiento de la legalidad parlamentaria permite el ejercicio de dichos derechos «el incumplimiento lo impide». Cuestión por la cual, los dos recursos de Ciudadanos acabarán aseverando que los acuerdos del Pleno «lesionaron el derecho de participación de los diputados recurrentes $[\ldots .$.$] al privársele del ejercicio de los derechos que la legalidad parlamentaria$ reconocía».

En definitiva, la inusual tramitación de dos proposiciones de ley a través de un art. 81.3 RPC gracias al cual la mayoría secesionista de la Mesa y el Pleno consideró que podía suprimirse una parte importante de los trámites parlamentarios, generó un Pleno insólito que duraría once horas. En él, mientras los favorables a la independencia acusaban al Estado de antidemocrático y a los grupos parlamentarios de C's, PSC y PP de filibusterismo por presentar una batería de solicitudes de reconsideración o de dictámenes del CGE con el objetivo de dilatar las votaciones y poder acudir al $\mathrm{TC}^{46}$; todos los grupos parlamentarios de la oposición afirmarían durante el proceso que se estaban infringiendo una pluralidad de preceptos reglamentarios, que se vulneraban sus derechos de participación política, que se incumplían las resoluciones del máximo intérprete constitucional y que las proposiciones de ley que iban a ser aprobadas infringían tanto el Estatuto de Autonomía catalán como la Constitución española. Cuestiones todas ellas que, como ya hemos visto, y aparte de las ya comentadas acciones judiciales del Gobierno y la fiscalía, darían lugar a diversas solicitudes de reconsideración que fueron inadmitidas por las Mesa del Parlamento de Cataluña y a sendos recursos de amparo tanto del grupo parlamentario Socialista como de Ciudadanos, estando los primeros resueltos en las SSTC 10/2018 y 27/2018 y los segundos a la espera de un pronunciamiento del máximo intérprete constitucional.

\section{LA JURISPRUDENCIA DEL TRIBUNAL CONSTITUCIONAL SOBRE LAS CUESTIONES PLANTEADAS DURANTE EL PROCEDIMIENTO DE APROBACIÓN DE AMBAS PROPOSICIONES DE LEY}

Una vez analizado el contenido del art. 81.3 RPC, el procedimiento a través del cual se aprobaron ambas proposiciones de ley, así como las consecuencias de ello en forma de recursos de amparo por presunta vulneración del ejercicio del cargo público ex art. 23.2 CE, resulta imprescindible examinar la doctrina que el máximo intérprete constitucional tiene sobre lo aseverado en el interior de estos recursos. Asimismo, como ya hemos visto que sobre el procedimiento que dio lugar a la aprobación de las proposiciones de ley de referéndum y transitoriedad se suscitó otra cuestión polémica que puede ser de interés pero que no ha sido alegada en ninguno de los recursos,

${ }^{46}$ No hubo críticas al grupo parlamentario de Catalunya Sí Que es Pot (CSQP) dado que no solicitó reconsideración o dictamen alguno. 
también se hará referencia a la doctrina que el máximo intérprete constitucional tiene sobre ella.

\subsection{La problemática de si la Mesa podía haber inadmitido a trámite ambas proposiciones de ley}

Por lo que respecta a dicha problemática expresada en las solicitudes de reconsideración que los diversos grupos parlamentarios de la oposición realizaron a la Mesa, el TC ha desarrollado una jurisprudencia consolidada donde se afirma que, si bien generalmente la función de control de la Mesa se limita a realizar un análisis de los requisitos formales en la admisión/inadmisión a trámite de las proposiciones de ley, fruto de «estar sujeta al ordenamiento jurídico, en particular a la Constitución y Reglamentos parlamentarios que regulan sus atribuciones y funcionamiento, y en aras de la mencionada eficiencia del trabajo parlamentario» (SSTC 10/2016 FJ 4 y 71/2017 FJ5), la Mesa puede de manera excepcional extender su examen más allá de la estricta verificación de dichos requisitos formales realizando una comprobación «liminar de la conformidad a Derecho de la pretensión deducida» (STC 205/1990 FJ 6 y 177/2002 FJ 6) siempre que «los escritos y documentos parlamentarios girados a la Mesa, sean de control de la actividad de los ejecutivos o sean de carácter legislativo, vengan [...] limitados materialmente por la Constitución, el bloque de la constitucionalidad o el Reglamento parlamentario pertinente» (STC 177/2002 FJ3) ${ }^{47}$. A lo que habría que añadir, como mínimo, el Derecho de la Unión Europea.

Una vez la Mesa decide extender su examen, según el TC ésta deberá rechazar los «escritos en los que se planteen cuestiones manifiestamente ajenas a las atribuciones de la Cámara», «contrarias a la Constitución o ajenas a las competencias atribuidas al ordenamiento en cuyo seno pretende integrarse» (STC 161/1988 FJ8 y 10/2016 FJ 4 respectivamente). Ahora bien, el propio TC pone dos límites a dicho deber. El primero es que el «examen de la iniciativa a la luz del canon normativo del Reglamento parlamentario» no esconda «un juicio sobre la oportunidad política» (STC 40/2003 FJ2), pues en ese caso se estaría vulnerando el ius in officium de los parlamentarios. Y el segundo límite es que «la Mesa sólo podría acordar la inadmisión cuando la contradicción a Derecho o la inconstitucionalidad de las proposiciones sean palmarias y evidentes» (STC 205/1990 FJ6 y 95/1994 FJ4). En suma, aunque generalmente el examen de la Mesa debe limitarse a realizar una comprobación formal de la proposición de ley, dicho escrutinio podrá extenderse en el caso que se planteen cuestiones entera y claramente limitadas desde el punto de vista material «por la Constitución, el bloque de la constitucionalidad o el reglamento parlamentario» (STC 57/2011 FJ 3; 203/2001 FJ 3); viéndose la Mesa finalmente obligada a acordar su inadmisión cuando, además, sean manifiestamente inconstitucionales o contrarios

${ }^{47}$ Cf. Fernández de Simón Bermejo, E.; Latorre Boluda M.; Martínez Conesa A. y Bas Carreras B. (2016), «Los órganos de dirección de los parlamentos», en Xosé Antón Sarmiento Méndez, Manual AELPA del Parlamentario, España, AELPA y Wolters Kluwer, pág. 119-122. 
a Derecho durante el examen liminar de las mismas ${ }^{48}$. Es decir, y como bien resumen las ATC 123/2017 FJ9, 124/2017 FJ9 y 144/2017 FJ7

«las Mesas de las Cámaras están facultadas para inadmitir a trámite las propuestas o proposiciones presentadas por los grupos parlamentarios cuya contradicción con el derecho o inconstitucionalidad sean "palmarias y evidentes"».

Una vez enmarcada ya la jurisprudencia del TC, es preciso ahora determinar si las proposiciones de ley que presentaron los grupos parlamentarios de JuntsxSí y la CUP cumplen con los requisitos para que la Mesa pudiera realizar un examen más allá de la estricta verificación de los requisitos formales, y si, de realizarlo, ésta hubiera tenido que inadmitir ambas proposiciones de ley por palmaria y evidente inconstitucionalidad. Sobre la primera cuestión, parece indudable que la Mesa podía haber realizado un análisis más allá de la verificación formal pues, mientras la ley de referéndum es una materia limitada por la Constitución (art. 23.1, 81.1, 92.3y 149.1.32) y la LO 2/1980, la de transitoriedad jurídica está limitada por los artículos 1, 2, 9.1 y $168 \mathrm{CE}$. Y, por lo que respecta a la segunda cuestión, la respuesta puede encontrarse en las SSTC 114/2017 FJ3 y 5 (sobre la Ley de referéndum) y 124/2017 FJ5 (sobre la Ley de transitoriedad), pues de ellas se puede extraer que, de haberse realizado dicho análisis hubieran tenido que inadmitirlas a trámite porque cada una de ellas es

«con toda evidencia, inconstitucional y lo es en su conjunto al contrariar, de modo explícito, principios esenciales de nuestro ordenamiento constitucional: la soberanía nacional, residenciada en el pueblo español, la unidad misma de la Nación constituida en Estado social y democrático de derecho, y la propia supremacía de la Constitución, a la que están sujetos todos los poderes públicos y también, por tanto, el Parlamento de Cataluña (arts. 1.2, 2, 1.1 y $9.1 \mathrm{CE}){ }^{49}$.

48 Cid Villagrasa B. (Dir.) (2014), El Parlamento ante los tribunales, Pamplona, Aranzadi, pág. 383387 y 540-541. Opinión diferente ostentará Xosé Antón Sarmiento Méndez, pues afirmará que «la calificación de la Mesa debe [...] limitarse a los aspectos meramente formales reglamentariamente exigidos [...] de lo contrario estaría asumiendo [...] una decisión política que sólo le corresponde al Pleno», Cf. «La función legislativa», en Iglesias Machado, S. y Marañón Gómez, R. (Coord.) (2016), Manual de derecho parlamentario autonómico, Madrid, Dykinson, pág. 265.

49 Añadiéndose en la STC 114/2017 FJ5, pero también aplicable a la Ley de transitoriedad que se trata «de una infracción constitucional que no es fruto, como suele ocurrir en las contravenciones de la norma fundamental, de un entendimiento equivocado de lo que la misma impone o permite en cada caso. Es resultado de un rechazo a la fuerza de obligar de la Constitución, a la que se contrapone de modo expreso un poder que se reclama depositario («representante», en palabras del art. 3.1 de la Ley) de una soberanía y expresión de una dimensión constituyente desde los que se ha llevado a cabo una manifiesta negación del vigente ordenamiento constitucional, un poder que se pretende fundante de un nuevo orden político y liberado, por ello mismo, de toda atadura jurídica». Cf. AATC 123/2017 FJ6 y 124/2017 FJ 5 y 6, pues en ambos autos se afirma que dichas proposiciones de ley «presuponen que el Parlamento de Cataluña se arroga atribuciones inherentes a la soberanía, superiores a las que derivan de la autonomía reconocida por la Constitución (SSTC 42/2014, FJ 2, y 259/2015, FJ 2) e insiste en introducir en el ordenamiento jurídico con apariencia de validez un objeto específico: el presunto «proceso constituyente» en Cataluña, cuya inconstitucionalidad ya declaró este Tribunal en la STC 259/2015 y reiteró en sus AATC 141/2016, 170/2016 y 24/2017, por desbordar los márgenes de actuación constitucionales y estatutarios del Parlamento de Cataluña». 
Así pues, la Mesa no tenía la obligación de admitir a trámite ambas proposiciones de ley como así afirmaban la mayoría de ésta y los servicios jurídicos del Parlamento de Cataluña ${ }^{50}$, sino que podía haber entrado a analizarlas por ser materias limitadas por la Constitución y el bloque de constitucionalidad. Cuestión que, de haberse realizado, hubiera comportado su inadmisión a trámite por contravenir frontalmente la Carta Magna. Sin embargo, la no realización de dichas acciones no supone una vulneración del art. $23 \mathrm{CE}$, pues el máximo intérprete constitucional entiende en su STC 107/2016 FJ3

«que las facultades de las Mesas de las asambleas en orden a la calificación y admisión a trámite de iniciativas parlamentarias lo son sobre todo a efectos de controlar la regularidad jurídica y la viabilidad formal o procesal de las iniciativas presentadas, de modo que las Mesas no deben, con carácter general, inadmitir propuestas o proposiciones a causa de la supuesta inconstitucionalidad de su contenido. Y aunque en casos excepcionales las Mesas pudieran pronunciarse en supuestos de palmaria y evidente inconstitucionalidad de una propuesta, el incumplimiento de un eventual control por parte de la Mesa, en dicha dirección, no ocasionaría infracción alguna del derecho fundamental (art. 23.2 CE) de quienes denuncien tal supuesta omisión de un control que habría sido obligado. Y ello porque el Tribunal Constitucional entiende que dentro del contenido del derecho de representación política contenido en el art. 23.2 CE, no se encuentra lo que habría de llamar "derecho fundamental a la constitucionalidad" de las iniciativas parlamentarias, o incluso, de los acuerdos o normas a que aboquen. Añadiendo que, en caso contrario, se alteraría al propio tiempo la propia configuración del recurso de amparo, e incluso, el entero sistema de nuestra justicia constitucional» ${ }^{51}$.

${ }^{50}$ Los servicios jurídicos del Parlamento catalán afirman delante del TC que «ni la Mesa del Parlamento estaría legitimada para ejercer un juicio de oportunidad o para conjeturar acercar de la apariencia de inconstitucionalidad de una proposición de ley, ni la Presidenta de la Cámara podía desoír la petición formulada por los grupos parlamentarios de alteración del orden del día del Pleno, al tratarse de un acto reglado conforme al artículo 81.3 RPC». Cf. ATC 123/2017 y 124/2017, pág. 19 y 17 respectivamente.

51 Dicha argumentación del TC se realiza contra lo afirmado en el recurso de amparo 6205-2015 por el que se pide declarar nulo el Acuerdo de la Mesa del Parlamento de Cataluña, de 27 de octubre de 2015, por el que se admite a trámite la «propuesta de resolución sobre el inicio del proceso político en Cataluña como consecuencia de los resultados electorales». En dicho recurso se afirma que se «estaría vulnerando claramente el artículo $23 \mathrm{CE}$ en el caso de que admitiera proposiciones que clara y palmariamente contrariasen la Constitución o el bloque de la constitucionalidad, plantearan cuestiones manifiestamente ajenas a la competencia del Parlamento o subvirtieran el mandato representativo. Ciertamente, la jurisprudencia constitucional referida a este precepto, hasta el momento, sólo ha apreciado vulneración de ese derecho fundamental en las decisiones de las Mesas de inadmisión a trámite de determinadas iniciativas [...] nunca antes ha tenido ocasión de pronunciarse el Tribunal Constitucional sobre una propuesta como la que nos ocupa en la que un Parlamento autonómico pretende, simple y llanamente, desconectarse del orden constitucional que legitima su actuación [.... Es obvio que una decisión de admitir a trámite una propuesta abierta y premeditadamente contraria a la Constitución, al Estatuto de Autonomía y a todo el orden constitucional español [...] supone una evidente vulneración del núcleo constitucionalmente protegido de la función representativa prevista en el artículo 23.2 de la CE y, al afectar a mandato representativos, también una grave conculcación del derecho del artículo 23.1 CE». 
Ahora bien, aunque todo lo anterior conllevaría la afirmación de que la Mesa del Parlamento de Cataluña no tenía la obligación de realizar un análisis más allá de la estricta verificación de los requisitos formales y que, por tanto, no tenía por qué inadmitir a trámite ambas proposiciones de ley, los incidentes de ejecución (AATC 141/2016, 170/2016, 24/2017) tras la STC 259/2015 que declaró inconstitucional y anuló «la resolución 1/XI del Parlamento de Cataluña sobre el inicio del proceso político en Cataluña como consecuencia de los resultados electorales del 27 de septiembre de 2015 y su anexo», no dejan lugar a dudas sobre cuáles eran las obligaciones de la Presidenta del Parlamento catalán y del conjunto de la Mesa

«los poderes públicos implicados y a sus titulares, especialmente a la Mesa del Parlamento de Cataluña, bajo su responsabilidad, de su deber de impedir o paralizar cualquier iniciativa que suponga alterar unilateralmente el marco constitucional o incumplir las resoluciones de este Tribunal. Tal admonición [...] es la consecuencia obligada de la sumisión a la Constitución de todos los poderes públicos (art. 9.1 CE)» 52 .

En definitiva, si bien en sentido genérico la Mesa tiene la posibilidad (que no la obligación) de realizar un análisis más allá de la estricta verificación de los requisitos formales cuando se planteen cuestiones entera y claramente limitadas desde el punto de vista material por la Constitución o el bloque de la constitucionalidad y, de realizarse éste, debe inadmitir los escritos y documentos parlamentarios girados a la Mesa cuando éstos sean manifiestamente inconstitucionales; en este caso concreto, la Mesa del Parlamento de Cataluña tenía tanto la obligación de realizar dicho análisis por existir unos incidentes de ejecución (AATC 141/2016, 170/2016, 24/2017) de la STC 259/2015 que le obligaban expresamente a ello, como el deber de acordar su inadmisión por ser las proposiciones de ley palmaria y evidentemente inconstitucionales. Deberes ambos cuya infracción no sólo ha conllevado la declaración de nulidad de los acuerdos de la Mesa de admisión a trámite de ambas proposiciones de ley, sino también ha supuesto que el Ministerio Fiscal deduzca testimonio y proceda a exigir responsabilidades penales tanto a la Presidenta del Parlamento de Cataluña como a todos aquellos miembros de la Mesa que hayan votado a favor de la admisión a trámite de ambas proposiciones de ley (AATC $123 / 2017$ y 124/2017).

Ahora bien, lo concluido en el párrafo anterior genera algunos posibles interrogantes que, si bien no corresponde al presente artículo solventar, creemos importante dejarlos manifestados para el caso de que se considere pertinente un análisis posterior. A saber, si según la doctrina del TC las Mesas de las Cámaras no están obligadas a entrar a valorar el contenido de las resoluciones o proposiciones de ley, pero la STC 259/2015 y los AATC 141/2016, 170/2016, 24/2017 obliga a ello a la Mesa del Parlamento de Cataluña, ¿se modifica entonces la propia doctrina del TC?, ¿deja

52 Puede encontrarse en los AATC 141/2016 FJ7, 170/2016 FJ 7 y 8, 24/2017 FJ9 y 10, 123/2017 FJ9 y 124/2017 FJ9. 
el examen de ser voluntario para ella y se convierte en un acto debido? ${ }^{53} \mathrm{Si}$ eso es así, ¿hasta cuándo se mantiene dicha obligación de control?, ¿se le añade de este modo una función impropia como es la de un control liminar de constitucionalidad? Y, por último, ¿suponen entonces los incidentes de ejecución el presupuesto procesal para llevar a cabo dicho examen? ${ }^{54}$ Es decir, ¿es posible que la obligación impuesta por el TC a la Mesa del Parlamento de Cataluña de impedir o paralizar cualquier iniciativa que suponga alterar unilateralmente el marco constitucional o incumplir las resoluciones de este Tribunal añada una función impropia a la Mesa como es la de un obligado control liminar de constitucionalidad? Y, de ser ello así, ¿no comportaría afirmar que el TC no puede obligar a la Mesa a realizar dicho examen y que, por tanto, no debería deducirse testimonio a los miembros de la Mesa del Parlamento de Cataluña a fin de exigirles responsabilidades penales?

\subsection{La problemática de si el artículo 81.3 RPC permite que a su través se desarrolle aquel procedimiento legislativo que se acabó utilizando para aprobar ambas proposiciones de ley}

Por lo que respecta a esta cuestión, evidenciada en el interior de los recursos de amparo de Ciudadanos, las SSTC 114/2017 FJ6 y 124/2017 FJ6 volverán a ser especialmente clarificadoras. Según ambas, para responder al interrogante formulado deben realizarse dos indicaciones previas. La primera es que el RPC únicamente posee un procedimiento legislativo común y diversos procedimientos especiales ${ }^{55}$, no existiendo fuera de éstos ningún otro procedimiento a través del cual el Reglamento permita legislar ${ }^{56}$. Y la segunda es que, el art. 81.3 RPC dispone

53 Cf. Arce Janariz, A. (mayo-agosto 1990), «Calificación y admisión a trámite en los procedimientos parlamentarios», Revista Española de Derecho Constitucional, Año 10, núm. 29.

${ }^{54}$ Otros interrogantes paralelos pueden ser los siguientes: ¿se modifica la doctrina constitucional sobre el examen de la homogeneidad y congruencia en las iniciativas legislativas al ser ahora un acto debido el examen material en la admisión/inadmisión a trámite? ¿se modifica el tradicional entendimiento de la prerrogativa de la inviolabilidad con esta nueva jurisprudencia constitucional? ¿debería dejarse de concebir el TC como un órgano de justicia constitucional concentrada y a posterior (a excepción de los casos de los Estatutos de Autonomía)? Y, por último, ¿dónde queda entonces la autonomía parlamentaria?

55 Los procedimientos especiales son los relativos a los proyectos y proposiciones de ley de desarrollo básico del Estatuto de Autonomía, al proyecto de ley de presupuestos, a la reforma del propio Estatuto de Autonomía, a la delegación en las comisiones de la competencia plena, a la tramitación de las iniciativas legislativas en lectura única y a la tramitación de las iniciativas legislativas populares.

56 Sobre el procedimiento legislativo en general véase: Rubio Llorente, F. (1986): «El procedimiento legislativo en España. El lugar de la ley entre las fuentes del Derecho», en Revista Española de Derecho constitucional, Año 6, núm. 16; García Martínez, M. A. (1987): El procedimiento legislativo, Madrid, Congreso de los Diputados; Arce Janáriz, A. (mayo-agosto 1993): «El procedimiento legislativo en el Principado de Asturias», en Revista Española de Derecho Constitucional, Año 13, Núm. 38; García Escudero, P. (2006): El procedimiento legislativo ordinario en las Cortes Generales, Madrid, CEPC; Sanz Pérez, A.L. (2011): «El procedimiento legislativo en la jurisprudencia Constitucional: los antecedentes, los plazos y las enmiendas», en Revista Aranzadi Doctrinal. 
«que el orden del día del Pleno puede ser alterado si este así lo acuerda a propuesta de dos grupos parlamentarios y añade que «si debe incluirse un asunto, este debe haber cumplido los trámites reglamentarios que lo permiten, salvo un acuerdo explícito en sentido opuesto, por mayoría absoluta» [... . Aun en el discutible caso de que pudiera acudirse a esa norma para incorporar al orden del día del Pleno, con pretensiones decisorias, un asunto que no hubiera culminado aún su tramitación legislativa previa, resulta innegable que para ello el procedimiento legislativo debiera estar al menos ya iniciado y en curso, a través de cualquiera de las vías previstas como "numerus clausus» en el Reglamento del Parlamento de Cataluña. Solo entonces, incoado ya y en marcha el procedimiento (el «común» o cualquiera de los especiales), serían también identificables los trámites realizados y los aún pendientes y la posibilidad o no de omitir o excluir fundadamente alguno de estos últimos para la incorporación del asunto a un orden del día del Pleno; posibilidad que en modo alguno puede decirse ilimitada, siendo como son los procedimientos parlamentarios, en general, garantía de los derechos de los representantes y, en particular, de las minorías» ${ }^{57}$.

Es decir, y expresado de manera sucinta, para el TC no parece ser manifiestamente inconstitucional que a través del art. 81.3 RPC se pueda modificar el orden del día para incluir el debate y votación de una proposición de ley. Ahora bien, para que ello suceda el procedimiento debe desarrollarse por alguna de las vías previstas en el propio RPC (ya sea el común o alguno de los especiales), estar incoado, haber cumplido los trámites reglamentarios previos que lo permiten y no quedar excluidos aquellos otros que son imprescindibles en cualquier tipo de procedimiento legislativo. Siendo esa la manera pertinente de conocer el conjunto de trámites a realizar, cuáles han sido ya ejecutados y cuáles pueden ser omitidos de los que todavía están pendientes.

Lo sucedido durante los días 6 y 7 de septiembre en el Pleno del Parlamento de Cataluña fue lo contrario a lo anteriormente afirmado, pues a través del art. 81.3 RPC se amparó la tramitación y aprobación de dos proposiciones de ley por una vía que estaba al margen de cualquiera procedimiento legislativo previsto en el propio RPC, creándose un procedimiento ad hoc donde la mayoría parlamentaria derogó y modificó una pluralidad de normas reglamentarias sin que mediara reforma previa del Reglamento. Así, de este modo, los diputados no obtuvieron la documentación objeto de debate y votación con cuarenta y ocho horas de antelación, se impidió solicitar dictamen del CGE, no se admitieron enmiendas a la totalidad y se concedieron sólo dos horas para las enmiendas al articulado. Como consecuencia de todo ello, las SSTC 114/2017 y 124/2017 acabarán estableciendo que si bien no es imposible interpretar que el art. 81.3 RPC permite incluir en el orden del día el debate y votación de proposiciones de ley,

«lo que no está en manera alguna en el artículo 81.3 RPC es una habilitación en favor de la mayoría para la creación a su arbitrio de «procedimientos» legislativos «extra ordinem»; ello llevaría a la conclusión absurda, e intolerable en derecho, de que todos y cada uno de los procedimientos efectivamente previstos y ordenados en el Regla-

${ }^{57}$ STC 114/2017 FJ6. 
mento del Parlamento de Cataluña serían ya meramente dispositivos y sustituibles, mediante libre decisión de aquella mayoría. Así se entendió aquí, sin embargo, por el Pleno del Parlamento de Cataluña, que recurrió a este expediente de alteración del orden del día cuando la iniciativa legislativa, recién admitida a trámite por la Mesa, no había iniciado siquiera su andadura procedimental por uno u otro de los cauces que el Reglamento dispone y sin que fueran conocidos los concretos trámites a seguir y, a partir de ello, los que pudieran acaso ser obviados. [...] la mayoría [...] innovó el Reglamento del Parlamento de Cataluña mismo y arbitró para el caso no la mera supresión, como sus portavoces dijeron, de uno u otro trámite procedimental, sino un «procedimiento» inédito que concibió e impuso a su conveniencia» ${ }^{58}$.

En definitiva, dado que lo sucedido los días 6 y 7 en el Parlamento de Cataluña fue que la mayoría parlamentaria creó un procedimiento que no estaba previsto en el RPC y como a través del art. 81.3 RPC sólo pueden incluirse en el orden del día proposiciones de ley cuyo procedimiento se desarrolle por alguna de las vías fijadas en el propio RPC, esté ya incoado y se hayan cumplido los trámites pertinentes, es plausible afirmar que el art. 81.3 RPC no habilita para que a su través se desarrolle aquel procedimiento legislativo que se acabó utilizando para aprobar ambas proposiciones de ley.

\subsection{La problemática sobre la supresión de la posibilidad de solicitar dictamen al CGE}

En cuanto a este asunto, evidenciado tanto en los recursos de amparo del grupo parlamentario Socialista como en una parte de los recursos de amparo de Ciudadanos, el TC afirmará que hay determinadas normas (en especial los Reglamentos parlamentarios) que tratan de «ordenar los derechos y facultades que corresponden a los distintos cargos y funciones públicas» (SSTC 161/1988 FJ7, 27/2000 FJ4 y 129/2013 FJ10), «de modo que, una vez reconocidos y configurados» éstos se integran «en su estatus representativo» (STC 143/2016 FJ3). Así pues, como esas «facultades de los parlamentarios [...] se ejercen y respetan en base al derecho» (STC 109/2016 FJ5), como la inobservancia de los preceptos que regulan el procedimiento legislativo puede viciar «de inconstitucionalidad la ley cuando se altere con ello, de modo sustancial, el proceso de formación de voluntad en el seno de las cámaras» (SSTC 99/1987 FJ1a, $103 / 2008$ FJ5, 185/2016 FJ5 y 215/2016 FJ 5) y como quiera también que la infracción del estatuto parlamentario representa una lesión del derecho fundamental cuando «queden afectados derechos o facultades que pertenezcan al núcleo de la función representativa parlamentaria» (STC 143/2016 FJ3), el derecho al procedimiento se acaba concibiendo como una parte del contenido esencial del art. $23.2 \mathrm{CE}^{59}$, pues la participación de los representantes políticos

«en el ejercicio de la función legislativa a través del procedimiento parlamentario reglamentariamente establecido para la concreta iniciativa objeto de tramitación y el

${ }^{58}$ STC 114/2017 FJ6.

59 Cid Villagrasa, B. (Dir.), El Parlamento ante los tribunales..., pág. 234-244. 
desempeño en el mismo de los derechos y facultades que lo acompañan constituye, en principio, una manifestación relevante del ius in officium de representante ${ }^{60}$.

En base a todo lo explicitado anteriormente, las SSTC 114/2017 y 124/2017 acabarán por afirmar que la solicitud de dictamen al CGE es

«una garantía que trae causa del propio Estatuto de Autonomía de Cataluña y que se incardina como tal facultad, por previsión de la Ley 2/2009 y del Reglamento del Parlamento de Cataluña, en el curso del procedimiento legislativo. En tanto que garantía en favor de la regularidad constitucional de las iniciativas legislativas y facultad también de los diputados y grupos legitimados al efecto, la posibilidad de pedir dicho dictamen no puede ser suprimida por la Cámara sin merma de la integridad del propio procedimiento legislativo y a la vez de los derechos de los representantes a ejercer esta concreta facultad que la ley les confiere y que se incorpora a su estatus jurídico-constitucional (art. 23.2 CE)» ${ }^{61}$.

Y, por tanto, que la mayoría del Pleno del Parlamento de Cataluña excluyera la posibilidad de solicitar un dictamen al CGE es una

«muy grave quiebra del procedimiento legislativo, que afectaron sin duda a la formación de voluntad de la Cámara, a los derechos de las minorías y a los derechos de todos los ciudadanos a participar en los asuntos públicos mediante representantes (art. 23.1 y $2 \mathrm{CE}){ }^{62}$.

En definitiva, las futuras sentencias del TC sobre dichos recursos de amparo acabarán fallando sobre unas problemáticas a las que no sólo les envuelve una doctrina consolidada, sino que también han sido directa (aunque tangencialmente) analizadas en el interior de dos sentencias donde se ha declarado la inconstitucionalidad tanto de la Ley de referéndum como la de transitoriedad. Como consecuencia, no parece ilógico pensar que las sentencias venideras del máximo intérprete constitucional se basen tanto en esa jurisprudencia consolidada como en la fundamentación jurídica que se realiza en las STC 114/2017 y 124/2017.

\section{UNA POSIBLE RESOLUCIÓN DE LOS RECURSOS DE AMPARO PRESENTADOS POR EL GRUPO PARLAMENTARIO DE CIUDADANOS}

Una vez examinado el contenido del art. 81.3 RPC, descrito tanto el proceso parlamentario que siguieron ambas proposiciones de ley como las problemáticas que en su interior se desarrollaron en relación al procedimiento, así como analizada también la doctrina del TC sobre las cuestiones planteadas en la sección anterior, es

60 STC 118/1999 FJ2.

${ }^{61}$ STC 114/2017 FJ6d y 124/2017 FJ6c.

62 STC 114/2017 FJ6e y 124/2017 FJ6d. 
oportuno concluir con una prospectiva de cuál podría ser la respuesta apropiada a los recursos de amparo presentados por el grupo parlamentario de Ciudadanos.

\subsection{En relación con los acuerdos del Pleno mediante los cuales se alteraba del orden del día para introducir las proposiciones de ley del referéndum y de transitoriedad}

De lo aseverado en el apartado 4.2, es posible extraer que en las SSTC 114/2017 y 124/2017 se desarrollan dos ideas cuya interpretación conjunta puede servir para resolver la presente cuestión. La primera es que no parece ser manifiestamente inconstitucional que a través del art. 81.3 RPC se pueda modificar el orden del día para incluir el debate y votación de una proposición de ley ${ }^{63}$. Y la segunda es que cada una de las dos proposiciones de ley (de referéndum y de transitoriedad) introducidas en el orden del día, es «con toda evidencia, inconstitucional y lo es en su conjunto al contrariar, de modo explícito, principios esenciales de nuestro ordenamiento constitucional» ${ }^{64}$.

La unión de ambas ideas permite el siguiente argumento jurídico: si bien el contenido de las dos proposiciones de ley vulnera la Norma Fundamental dado que pretenden alterar unilateralmente el marco constitucional, la legalidad del procedimiento al poderse modificar el orden del día para incluir el debate y votación de proposiciones de ley a través del art. 81.3 RPC, hace que en ningún momento se vea comprometido el ejercicio en condiciones de igualdad del cargo público o la democrática formación de la voluntad de las cámaras. O, dicho de otro modo, la evidente inconstitucionalidad del contenido de las proposiciones de ley que el Pleno acordó introducir en el orden del día, no comporta que el acuerdo plenario de la alteración del orden del día vulnere el contenido esencial del art. 23.2 CE por dos razones: la primera porque en todo momento los parlamentarios han podido ejercer las facultades inherentes a su cargo que del RPC se desprenden, y la segunda porque

«dentro del contenido del derecho de representación política contenido en el art. 23.2 $\mathrm{CE}$, no se encuentra lo que habría de llamar «derecho fundamental a la constitucionalidad» de las iniciativas parlamentarias, o incluso, de los acuerdos o normas a que aboquen. Añadiendo que, en caso contrario, se alteraría al propio tiempo la propia configuración del recurso de amparo, e incluso, el entero sistema de nuestra justicia constitucional» ${ }^{65}$.

Así pues, por mucho que las proposiciones de ley de referéndum y de transitoriedad infrinjan de manera palmaria la Constitución, los acuerdos del Pleno mediante los cuales se altera del orden del día para introducir dichas proposiciones de ley no parece que vulneren el contenido esencial del art. 23.2 CE. Opinión esta que, de ser

${ }^{63}$ STC $114 / 2017$ FJ6.

${ }^{64}$ STC 114/2017 FJ5 y STC 124/2017 FJ5.

${ }^{65}$ STC 107/2016 FJ3. 
compartida por el TC en la futura sentencia, comportaría que dichos acuerdos no fueran anulados tal y como pedía el grupo parlamentario de Ciudadanos en el recurso de amparo.

\subsection{En relación con los acuerdos del Pleno mediante los cuales se creaba un procedimiento legislativo ad hoc para proceder al debate y votación definitiva de las proposiciones de ley del referéndum y de transitoriedad}

Partiendo de la base de que el art. 81.3 RPC no habilita para que mediante su utilización la mayoría parlamentaria cree un procedimiento legislativo nuevo gracias al cual posteriormente se puedan aprobar proposiciones de ley, pues es imprescindible que éste se desarrolle por alguna de las vías previstas en el propio RPC (ya sea el común o alguno de los especiales), esté incoado, haya cumplido los trámites reglamentarios previos que lo permiten y no se encuentren incluidos aquellos otros que son imprescindibles en cualquier tipo de procedimiento legislativo; que de no interpretarse el art. 81.3 RPC así estaríamos ante la quiebra tanto del Estado de derecho como de la democracia parlamentaria al permitir que la mayoría dispusiera arbitrariamente del procedimiento legislativo y pudiera eliminar tanto el pluralismo político como el derecho de las minorías ${ }^{66}$; que fue precisamente eso lo que sucedió los días 6 y 7 de septiembre en el Parlamento de Cataluña al gestar la mayoría parlamentaria un procedimiento legislativo ad hoc no contemplado en el propio RPC; y que, finalmente, el derecho al procedimiento es una parte del contenido esencial del art. 23.2 CE pues la participación de los representantes políticos «en el ejercicio de la función legislativa a través del procedimiento parlamentario reglamentariamente [...] constituye [...] una manifestación relevante del ius in officium de representante» ${ }^{67}$.

Parece lógico concluir que las leyes de referéndum y transitoriedad no sólo son inconstitucionales por no respetar el orden material y competencial (SSTC 114/2017 y 124/2017), sino también porque el procedimiento creado ad hoc para aprobarlas vulnera de manera flagrante el art. 1.1 y 23.2 CE. Es decir, que dicho procedimiento infringe el Estado de Derecho al supeditar el ordenamiento jurídico a la mera voluntad de una mayoría que modifica el RPC sin utilizar los mecanismos legalmente establecidos y vulnera tanto la democracia parlamentaria como el pluralismo político dado que lo anterior implica la sumisión de la minoría a la voluntad arbitraria de la mayoría, debiéndose tener en cuenta que la representación política sólo puede desarrollarse democráticamente si se

«atienen en general a los procedimientos que el ordenamiento dispone y, más concretamente, a las reglas jurídicas que, integradas sobre todo en los reglamentos de las

\footnotetext{
${ }^{66}$ Sobre dicha cuestión véase Requejo Rodríguez, P. (2000): Democracia parlamentaria y principio minoritario, Barcelona, Ariel.

67 STC 118/1999 FJ2.
} 
Cámaras, aseguran una participación no discriminatoria de unos y otros representantes. Se asegura con ello el necesario respeto de las minorías, sin el cual el principio de mayoría para la adopción final de las decisiones, igualmente irrenunciable, pondría en riesgo su legitimidad. La democracia parlamentaria no se agota, ciertamente, en formas y procedimientos, pero el respeto a unas y otros está, sin duda, entre sus presupuestos inexcusables» ${ }^{68}$.

Y, además, también infringe el derecho de ejercicio del cargo público (art. 23.2 CE) porque si el derecho al procedimiento reglamentariamente fijado es una parte del ius in officium, la vulneración del mismo no sólo comporta una infracción del núcleo esencial de la función representativa parlamentaria porque impide ejercer las concretas facultades que la ley confiere a los diputados y que se incorporan a su estatus jurídico-constitucional, sino que igualmente perturba la democrática formación de la voluntad de las Cámaras dado que únicamente el respeto al procedimiento puede hacer legítimos los deseos del legislador y garantizar el derecho de las minorías.

Así pues, si el TC siguiera la argumentación jurídica realizada hasta el momento, en la futura sentencia debería fallar a favor del grupo parlamentario de Ciudadanos anulando los acuerdos del Pleno mediante los cuales se creó un procedimiento legislativo ad hoc para acabar aprobando las leyes de referéndum y transitoriedad por darse una vulneración del art. 23.2 CE.

\section{LAS SSTC 10/2018 Y 27/2018 QUE RESUELVEN LOS RECURSOS DE AMPARO SOBRE LOS ACUERDOS DE LA MESA POR LOS QUE SE DESESTIMABA LA SOLICITUD DE DICTAMEN DEL CGE ${ }^{69}$}

Las presentes sentencias resuelven, de manera idéntica, la problemática anteriormente planteada de si los acuerdos de la Mesa de los días 6 y 7 de septiembre de 2017 mediante los cuales se inadmitieron las solicitudes del grupo parlamentario Socialista para que el CGE emitiera un dictamen sobre la adecuación de las proposiciones de ley de referéndum y de transitoriedad a la Constitución y al Estatuto de Autonomía catalán vulneraron el art. $23.2 \mathrm{CE}$.

Ambas se inician rechazando la solicitud de desestimación presentada por la representación del Parlamento de Cataluña ${ }^{70}$ en base a cuatro argumentos concatenados. El

68 STC 109/2016 FJ 5

69 Aunque dichas sentencias únicamente resuelvan los recursos de amparo presentados por el grupo parlamentario socialista, la misma petición puede encontrarse en los recursos de amparo del grupo parlamentario de Ciudadanos que aún no han sido abordados por el TC.

${ }^{70}$ Dicha representación alegará que «la inadmisión de la solicitud de dictamen del Consejo de Garantías Estatutarias no trae causa en un acuerdo de la Mesa del Parlamento de Cataluña, sino en la previa aprobación, por la mayoría del Pleno, de una alteración del orden del día, así como en la supresión de determinados trámites reglamentarios, todo ello con apoyo en el artículo 81.3 del Reglamento del 
primero es que los acuerdos de la Mesa impugnados forman parte de un procedimiento que ya fue declarado inconstitucional por las SSTC 114/2017 y 124/2017 al articularse un procedimiento legislativo no previsto en el Reglamento que vulneraba el pluralismo político del art. 1.1 $\mathrm{CE}^{71}$. El segundo es que lo anterior tiene conexión directa con los recursos de amparo analizados, pues el no respeto a dicho pluralismo puede afectar al derecho de las minorías y, por tanto, al ejercicio en condiciones de igualdad del cargo público ex art. 23.2 $\mathrm{CE}^{72}$. El tercero es que, no es posible a través del art. 81.3 RPC crear un procedimiento legislativo ad hoc que deje al albur de la mayoría derechos de la minoría, pues se afirma en ambas sentencias que, de interpretarse ello así, podría llegarse a la aciaga conclusión de que «todos y cada uno de los procedimientos efectivamente previstos y ordenados en el Reglamento del Parlamento de Cataluña serían ya meramente dispositivos y sustituibles, mediante libre decisión de aquella mayoría» ${ }^{73}$. Y el cuarto es que, en Cataluña, todo procedimiento legislativo (tanto el común como el especial) tiene una serie de trámites inexcusables para su validez entre los que está la facultad de pedir un Dictamen al CGE (76 EAC y 120 RPC $)^{74}$, pudiendo este último dictaminar específicamente sobre «la adecuación al presente Estatuto y a la Constitución de los proyectos y las proposiciones de ley sometidos a debate y aprobación del Parlamento y de los Decretos leyes sometidos a convalidación del Parlamento» (art. 76.2.b EAC). Asimismo, como sobre dicho trámite inexcusable recae una reserva material de ley (art. 77.3 EAC), que se concreta en una norma básica de desarrollo del Estatuto de Autonomía (art. 62.2 EAC y art. 16.1.b y 26bis LCGE), los requisitos para solicitar un dictamen al CGE ni siquiera pueden ser modificados por el Reglamento parlamentario catalán, configurándose dicha facultad como una parte del ius in officium del cargo público representativo ${ }^{75}$.

Parlamento de Cataluña (RPC), explicando que la apertura del trámite de solicitud de dictamen del Consejo de Garantías está previsto en el procedimiento legislativo común (art. 120 RPC), pero no, según la letrada, cuando se da una alteración del orden del día y la mayoría parlamentaria decide suprimir determinados trámites del procedimiento legislativo, añadiendo que, en todo caso, el derecho a solicitar un dictamen del Consejo de Garantías Estatutarias no forma parte de las facultades integradas en el núcleo esencial del ius in officium de los diputados del Parlamento de Cataluña, por lo que no cabe hablar de una vulneración del artículo 23.2 CE». Cf. SSTC 10/2028 FJ1 y 27/2018 FJ1.

71 STC 10/2018 FJ3 y 27/2018 FJ3.

72 STC 10/2018 FJ4 y 27/2018 FJ4.

${ }_{73}$ SSTC 10/2018 FJ4 y 27/2018 FJ4. Cf. STC 114/2017 FJ6c.

74 También están la publicación (106.3 y 112 RPC) y la tramitación al ejecutivo para que determine si existe afectación presupuestaria (111.2 RPC).

75 Sobre el CGE en general, véase: Vintró Castells, J. (2009), «La incidencia dels dictàmens del Consell de Garanties Estatutaries en l'exercici de la funció legislativa del Parlament», en Activitat Parlamentària, Núm. 18, págs. 26-41; Pla i Boix, A. (2009), «Composició, organització i estatut dels membres del Consell de Garanties Estatutàries», en Activitat Parlamentària, Núm. 18, págs. 17-25; Navas Castillo, F. (2009), «El consejo de garantías estatutarias de la Generalitat de Cataluña», en Vera Santos, JM; Díaz Revorio, FJ. (Coord.)(2009), La reforma estatutaria y constitucional, La Ley, pág. 363-403; Fossas Espadaler, E. (2011), «El Consejo de Garantías Estatutarias como garante de la autonomía política», en Biglino Campos, P. y Mapelli Marchena, C. (dir.), Garantías del pluralismo territorial, CEPC, Fundación 
Una vez rechazada la solicitud de desestimación presentada por la representación del Parlamento de Cataluña, constatado que la posibilidad de solicitar dictamen al CGE es un trámite inexcusable del procedimiento legislativo sobre el que recae una reserva material de ley, afirmado que dicho precepto es un parámetro de estatutariedad cuya función es dotar del más alto nivel de garantías a las minorías para controlar la constitucionalidad de todas las leyes que se pretendan aprobar en el parlamento, recordada la doctrina consolidada sobre el contenido esencial del art. $23.2 \mathrm{CE}^{76}$ y teniendo muy presente tanto lo aseverado por el CGE (véase nota 25) como lo establecido en las SSTC 114/2017 FJ6d y 6e, 124/2017 FJ6c y 6d ${ }^{77}$; ambas sentencias concluyen que la exclusión por parte del procedimiento ad hoc de la posibilidad de acudir al CGE no sólo contraviene el Estatuto de Autonomía de Cataluña, la ley 2/2009 y el RPC, sino que también acaba vulnerando el derecho de ejercicio del cargo público fijado en el art. 23.2 CE. Y eso es así por dos razones: la primera porque al configurarse dicha facultad como una parte del ius in officium, su mera eliminación comporta una infracción del núcleo esencial de la función representativa parlamentaria; $y$, la segunda, porque la quiebra del procedimiento legislativo también perturba la democrática formación de la voluntad de las Cámaras dado que sólo el respeto al mismo puede hacer legítimo los deseos del legislador y garantizar el derecho de las minorías ${ }^{78}$.

Manuel Giménez Abad y Forum of Federations, págs. 209-227; de Miguel Bárcena, J. (2011), «El Consejo de Garantías Estatutarias de Cataluña, en el laberinto del Derecho Parlamentario», en Biglino Campos, P. y Mapelli Marchena, C. (dir.), Garantías del pluralismo territorial, CEPC, Fundación Manuel Giménez Abad y Forum of Federations, págs. 229-247; Carrillo, M. (junio/julio 2017), «El Consell de Garanties Estatutàries», en Món Jurídic. Revista de l'il.lustre col.legi de l'advocacia de Barcelona, Núm. 312, pág 22-25. Asimismo, en relación al CGE como garantía de los Derechos véase: Albertí Rovira, E. (2008), «El nou Consell de Garanties Estatutàries de l'Estatut d'Autonomia de Catalunya com a instrument de garantia dels drets», en Borrell i Mestre, J.; Camps Rovira, J.; Sieira Míguez, JM. (Coord.), Autonomía y Justicia a Catalunya, Consell Consultiu de la Generalitat de Catalunya, págs. 119-126; Delgado del Rincón, L. (2011), «El Consejo de Garantías Estatutarias de Cataluña de órgano consultivo de la Generalidad a órgano de control jurídico y de tutela institucional de los derechos estatutarios», en Matia Portilla, FJ. (Coord.), Pluralidad de ciudadanías, nuevos derechos y participación democrática, CEPC, págs. 225-255; Delgado del Rincón, L. (2012), «El consejo de Garantías Estatutarias de Cataluña como órgano consultivo de la Generalidad y de garantía institucional de los derechos estatutarios», en Cascajo Castro, JL.; Terol Becerra, MJ.; Domínguez Vila, A.; Navarro Marchante, V. (Coord.), Derechos sociales y principios rectores: Actas del IX Congreso de la Asociación de Constitucionalistas de España, Tirant lo Blanc, págs. 193-214.

${ }^{76}$ Nos referimos a que, una vez reguladas las facultades de los parlamentarios «se integran en su estatus representativo» (STC 143/2016 FJ3), que la inobservancia de los preceptos que regulan el procedimiento legislativo puede viciar «de inconstitucionalidad la ley cuando se altere con ello, de modo sustancial, el proceso de formación de voluntad en el seno de las cámaras» (SSTC 99/1987 FJ1a, 103/2008 FJ5, 185/2016 FJ5 y 215/2016 FJ 5) y que el derecho al procedimiento se acaba concibiendo como una parte del contenido esencial del art. 23.2 CE por constituir «una manifestación relevante del ius in officium de representante» (STC 118/1999 FJ2). Cf. SSTC 10/2018 FJ 3 a, b, c y 27/2018 FJ3 a, b, c.

77 SSTC $10 / 2018$ FJ5 y 27/2018 FJ5.

${ }^{78}$ SSTC 10/2018 FJ5-6 y 27/2018 FJ5-6. 
En suma, ambas sentencias establecen que procedía tramitar cada una de las solicitudes de dictamen del CGE y, por tanto, que su no realización no solo comporta declarar lesionado el derecho de ejercicio del cargo público en condiciones de igualdad ex art. 23.2CE, sino también la nulidad de los Acuerdos de la Mesa de los días 6 y 7 de septiembre por los que se desestimaba tramitar la solicitud de dicho dictamen $^{79}$.

\section{CONCLUSIÓN}

Para finalizar bueno será recapitular las conclusiones de los diversos apartados antes de efectuar una postrera reflexión:

1) La Mesa del Parlamento de Cataluña no sólo puede realizar un análisis más allá de la estricta verificación de los requisitos formales cuando se planteen cuestiones entera y claramente limitadas desde el punto de vista material por la Constitución o el bloque de la constitucionalidad, sino que, en este caso concreto que nos ocupa, tenía tanto la obligación de realizarlo por existir unos incidentes de ejecución (AATC 141/2016, 170/2016, 24/2017) de la STC 259/2015 que le obligaban expresamente a ello, como el deber de acordar su inadmisión por ser las proposiciones de ley palmaria y evidentemente inconstitucionales.

2) El máximo intérprete constitucional debería fallar en contra de la parte del recurso de Ciudadanos donde se pide anular los acuerdos del Pleno mediante los cuales se alteró el orden del día para introducir las proposiciones de ley del referéndum y transitoriedad a través del art. 81.3 RPC al no vulnerarse, en mi opinión, el art. 23.2 CE. Pero, en cambio, debería resolver a favor de aquella otra parte del mismo recurso donde se pedía anular los acuerdos del Pleno mediante los cuales se creó un procedimiento legislativo ad hoc a través del art. 81.3 RPC para acabar aprobando las leyes de referéndum y transitoriedad por infringir el art. 23.2 CE.

3) El TC ha estimado positivamente los recursos de amparo del grupo parlamentario Socialista en los que se pedía declarar la nulidad de los Acuerdos de la Mesa de los días 6 y 7 de septiembre por los que se desestimaba tramitar la solicitud de dicho dictamen, pues ello contravino el derecho de ejercicio del cargo público ex art. 23.2 CE.

Por último, considero útil acabar estas líneas aseverando tres afirmaciones que también se desprenden del texto:

79 SSTC 10/2018 FJ7 y 27/2018 FJ7. 
Primero, que no parece ser manifiestamente inconstitucional que a través del art. 81.3 RPC se pueda modificar el orden del día para incluir el debate y votación de una proposición de ley, afirmación esta que bien puede ser ampliable a todos aquellos preceptos de los demás reglamentos parlamentarios cuyo contenido sea similar.

Segundo, que ni el art. 81.3 RPC ni ningún otro precepto que desarrolle la alteración del orden del día en los demás reglamentos parlamentarios, habilita para que a su través la mayoría parlamentaria cree un procedimiento legislativo ad hoc gracias al cual posteriormente se puedan tramitar proposiciones de ley, pues en cualquiera de ellos es imprescindible que se desarrolle por alguna de las vías previstas en el propio Reglamento, que esté incoado, que haya cumplido los trámites reglamentarios previos que lo permiten y que no queden excluidos aquellos otros que son imprescindibles en cualquier tipo de procedimiento legislativo.

Y tercero, que el motivo principal por el cual se acabaron tramitando las proposiciones de ley de esa manera no es otro que la voluntad del gobierno catalán y la mayoría parlamentaria que lo sustentaba de tramitar y aprobar con apariencia de legalidad dos proposiciones de ley que eran ya en su origen evidentemente inconstitucionales ${ }^{80}$. Y, además, de realizarlo buscando que dicha tramitación se ejecutase de manera rápida para poderlas aprobarla sin que hubiera una impugnación del Gobierno, una suspensión por parte del TC antes de que éstas fueran votadas en el parlamento autonómico catalán, un Dictamen negativo del CGE y un debate parlamentario ordinario que proyectara de forma continuada hacia la opinión pública lo que en realidad estaban haciendo: a saber, vulnerar el derecho de ejercicio del cargo público en condiciones de igualdad y, por ende, el de participación política de los ciudadanos, al retorcer intencionadamente el procedimiento legislativo hasta el punto de que éste no fuera más que la simple voluntad de la mayoría parlamentaria de aquel momento.

Title:

The alteration of the agenda to approve the referendum and transitoriness laws. The use of article 81.3 of the standing orders of the Parliament of Catalonia.

${ }^{80}$ Cuestión que posteriormente el TC se ha encargado de confirmar a través de las STC 114/2017 y $124 / 2017$. 


\section{Summary:}

1. Introduction. 2. The content of article 81.3 Of the standing orders of the parliament of catalonia. 3. The consequences of the use of article $81.3 \mathrm{Rpc}$ to introduce the laws of referendum and transitoriness on the agenda. 4 . The jurisprudence of the constitutional court on the questions raised during the procedure to approve both bills. 4.1 The problem of whether the Parliamentary Bureau could have inadmitted to process both bills. 4.2 The problem of whether art. 81.3 RPC allows through it to develop that legislative procedure that was eventually used to approve both bills. 4.3 The problem regarding the suppression of the possibility of requesting a Dictum from the Council of Statutory Guarantees. 5. A possible resolution of the appeal submitted by the ciudadanos parliamentary group. 5.1 In relation to the plenary agreements by means of which the agenda was changed to introduce the bills of the referendum and of transitoriness. 5.2 In relation to the agreements of the Plenary through which an ad hoc legislative procedure was created to proceed to the debate and definitive voting of the bills of the referendum and of transitoriness. 6. The sstc 10/2018 and 27/2018 that solve the appeal in relation to the agreements of the parliamentary bureau that rejected the request for the cge's dictum. 7. Conclusion.

\section{Resumen:}

La presente investigación trata de analizar el uso que se hizo del artículo 81.3 del Reglamento del Parlamento de Cataluña para alterar el orden del día y aprobar tanto la proposición de ley de referéndum como la de transitoriedad. Para ello, primero se ha examinado tanto el contenido que posee dicho artículo como aquellas cuestiones dudosas sobre el mismo. En segundo lugar, se ha resumido tanto la interpretación que se le dio a dicho precepto por la mayoría parlamentaria catalana para poder introducir ambas proposiciones de ley como las consecuencias que ello tuvo en forma de recursos de amparo. En tercer lugar, se ha contrastado la jurisprudencia del Tribunal Constitucional con las diferentes cuestiones planteadas durante el procedimiento de aprobación de ambas proposiciones de ley. En cuarto lugar, se ha intentado realizar una propuesta de resolución de aquellos recursos de amparo presentados por el grupo parlamentario de Ciudadanos sobre los que el Tribunal Constitucional todavía no se ha pronunciado. Y, en quinto y último lugar, se ha analizado las SSTC 10/2018 y 27/2018 que resuelven los recursos de amparo sobre los acuerdos de la Mesa por los que se desestimaba la solicitud de dictamen del CGE.

Una vez realizado todo ello, seis han sido las principales conclusiones. Uno: que la Mesa del Parlamento de Cataluña tenía tanto la obligación de realizar un análisis más allá de la estricta verificación de los requisitos formales por existir unos incidentes de ejecución que le obligaban expresamente a ello, como el deber de acordar su inadmisión por ser las proposiciones de ley palmaria y evidentemente inconstitucionales. Dos: que el 
Tribunal Constitucional debería fallar en contra de la parte del recurso de Ciudadanos donde se pedía anular los acuerdos del Pleno mediante los cuales se alteró el orden del día, pero debería resolver a favor de aquella otra parte del mismo recurso donde se pedía anular los acuerdos del Pleno mediante los cuales se creó un procedimiento legislativo ad hoc a través del art. 81.3 RPC. Tres: que las SSTC 10/2018 y 27/2018 estiman positivamente los recursos de amparo del grupo parlamentario Socialista en los que se pedía declarar la nulidad tanto de los Acuerdos de la Mesa de los días 6 y 7 de septiembre por los que se desestimaba tramitar la solicitud de dicho dictamen como de sus efectos. Cuatro: que no parece ser manifiestamente inconstitucional que a través del art. 81.3 RPC se pueda modificar el orden del día para incluir el debate y votación de una proposición de ley, afirmación esta que bien puede ser ampliable a todos aquellos preceptos de los demás reglamentos parlamentarios cuyo contenido sea similar. Cinco: que ni el art. 81.3 RPC ni ningún otro precepto que desarrolle la alteración del orden del día en los demás reglamentos parlamentarios, habilita para que a su través la mayoría parlamentaria cree un procedimiento legislativo ad hoc gracias al cual posteriormente se puedan aprobar proposiciones de ley. Y seis: que el motivo principal por el cual se acabaron tramitando las proposiciones de ley de esa manera no es otro que la voluntad de la mayoría parlamentaria (y, por ende, del Gobierno catalán) de tramitar y aprobar con apariencia de legalidad dos proposiciones de ley que eran ya en su origen evidentemente inconstitucionales.

\section{Abstract:}

The present investigation tries to analyse the use that was made of article 81.3 of the Catalan Parliamentary rules of procedure to alter the order of the day and approve both the Referendum Law and the Transitoriness Act. For this, first the content of the article as well as the dubious questions about it have been examined. Secondly, the interpretation given to this precept by the Catalan parliamentary majority in order to introduce both bills as well as the consequences that it had in the form of appeals has been summarized. Thirdly, the jurisprudence of the Constitutional Court has been contrasted with the different issues raised during the approval procedure of the Referendum and Transitoriness Acts. Fourthly, an attempt has been made to make a proposal for a resolution of the appeals filed and on which the Constitutional Court has not yet ruled. And fifthly, analyse the STCC 10/2018 and 27/2018 that solve the appeal in relation to the agreements of the Parliamentary Bureau that rejected the request for the CGE's dictum.

Once all this has been done, six have been the main conclusions. One: that the Catalan Parliament Bureau was so obliged to carry out an analysis beyond the strict verification of the formal requirements because there were some execution incidents that expressly obliged it, as well as the duty to agree on its inadmissibility because the proposals were of obvious law and 
evidently unconstitutional. Two: that the Constitutional Court should rule against the part of the Citizens' appeal where it was requested to annul the agreements of the Plenary by means of which the agenda was altered, but it should resolve in favour of that other part of the same resource where it was requested cancel the agreements of the Plenary through which an ad hoc legislative procedure was created through art. 81.3 RPC. Three: that the SSTC 10/2018 and 27/2018 positively estimate both the appeal of the Socialist parliamentary group and one of the parties to the appeal for protection of Citizens, in which it was requested to declare the nullity of both the Agreements of the Bureau of the 6th and September 7 for which it was rejected to process the request for such opinion and its effects. Four: it does not seem to be manifestly unconstitutional that, through art. 81.3 RPC, the agenda can be modified to include the debate and vote on a proposed law, an affirmation that may well be extended to all those precepts of the other regulations parliamentarians whose content is similar. Five: that neither art. 81.3 RPC nor any other precept that develops the alteration of the agenda in the other parliamentary regulations, enables the parliamentary majority to create an ad hoc legislative procedure through which subsequent proposals can be approved. Of law. And six: that the main reason why they ended up processing the proposals of law in this way is none other than the will of the Catalan parliamentary majority (and, thus his government) to process and approve with appearance of legality two propositions of law that were already in their origin evidently unconstitutional.

\section{Palabras claves:}

Alteración del orden del día, Derecho Parlamentario, Consejo de Garantías Estatutarias, inadmisión a trámite de la Mesa, Ley de referéndum y transitoriedad.

\section{Key words:}

alteration of the agenda, standing orders of the parliament, Council of Statutory Guarantees, inadmissibility by the Parliamentary Bureau, referendum and transitoriness laws.: 